\title{
Féeries
}

Études sur le conte merveilleuX, XVII ${ }^{-}$XIXe siècle

\section{Une réécriture apostolique de « La Belle au bois dormant » en Espagne : "La victoria de la cruz. Cuento de hadas ", de Pedro de Madrazo (1895)}

An Apostolic Rewriting of "Sleeping Beauty" in Spain: Pedro de Madrazo's "La victoria de la cruz. Cuento de hadas" (1895)

\section{Justine Pédeflous}

\section{OpenEdition \\ Journals}

Édition électronique

URL : http://journals.openedition.org/feeries/881

DOI : 10.4000/feeries.881

ISSN : 1957-7753

Éditeur

UGA Éditions/Université Grenoble Alpes

Édition imprimée

Date de publication : 20 septembre 2013

Pagination : 59-95

ISBN : 978-2-84310-253-0

ISSN : $1766-2842$

\section{Référence électronique}

Justine Pédeflous, « Une réécriture apostolique de « La Belle au bois dormant » en Espagne : « La victoria de la cruz. Cuento de hadas », de Pedro de Madrazo (1895) », Féeries [En ligne], 10 | 2013, mis en ligne le 20 mars 2015, consulté le 08 septembre 2020. URL : http://journals.openedition.org/feeries/ $881 ;$ DOl : https://doi.org/10.4000/feeries.881 


\section{UNE RÉÉCRITURE APOSTOLIQUE DE «LA BELLE AU BOIS DORMANT» EN ESPAGNE : "LA VICTORIA DE LA CRUZ. CUENTO DE HADAS", DE PEDRO DE MADRAZO (1895)}

$P$ EDRO DE MADRAZO Y KUNTZ (I8I6-I898), frère cadet du célèbre peintre royal Federico de Madrazo, est moins connu en Espagne malgré une carrière brillante de critique et d'historien de l'art. Il dirigea le Musée d'Art Moderne de Madrid et fut membre de plusieurs académies espagnoles ${ }^{1}$. Dans le domaine littéraire, il est surtout connu pour avoir collaboré à une importante publication périodique du XIX ${ }^{\mathrm{e}}$ siècle espagnol, El Artista (I835-1836), inspirée de la revue française L'Artiste (I83I-I9O4). Malgré sa courte durée de vie, cette revue joua un grand rôle dans le développement artistique et littéraire de l'Espagne post-fernandine, accueillant dans ses pages les nouveautés européennes, telles que le romantisme (en art et en littérature) ou la littérature fantastique. Pedro de Madrazo lui-même produisit de nombreux poèmes influencés par le romantisme, et un conte fantastique inspiré d'Hoffmann ${ }^{2}$. Il s'agit du récit le plus novateur et subversif de la revue car il est régi par le principe d'ambiguïté aussi bien en ce qui concerne le traitement du surnaturel que dans le domaine moral. Jusqu’à la fin de sa vie, il continuera de collaborer aux revues les plus importantes de l'époque en tant que nouvelliste et poète 3 .

I. Il fut membre en I842 puis directeur en 1894 de la Real Academia de Bellas Artes de San Fernando en I842, membre de la Real Academia de Historia en I858 et de la Real Academia de la Lengua en I88I.

2. P. de Madrazo, "Yago Yasck (cuento fantástico)", dans El Artista, t. III, I836, n 3, 4, 5 .

3. Trois de ses récits ("Alberto Regadon», qui ne contient aucun élément surnaturel, «Yago Yasck» et "Una impresión supersticiosa", dont nous reparlerons) ont été publiés en recueil par B. Rodríguez Gutiérrez (éd.), Cuentos, Pedro de Madrazo, Santander, Servicio de Publicaciones, Universidad de Cantabria, 2004. Borja Rodríguez indique également à la page 49 les autres œuvres de Pedro de Madrazo publiées dans la presse. 
Son œuvre est marquée par une nette évolution du fantastique vers le merveilleux et de la subversion vers la conformité morale. Le récit «Una impresión supersticiosa ${ }^{4}$ », publié en 1837 et donc peu de temps après son premier conte, est encore proche du fantastique hoffmannien. Par la suite, Madrazo publia plusieurs légendes religieuses, telles que "El hidalgo de Arjonillas", qui reprend la thématique donjuanesque du châtiment divin du séducteur impie, féconde dans la littérature espagnole ${ }^{6}$. Dans ces récits, on est loin de l'ambiguïté du premier conte, tant au niveau du traitement du surnaturel que de son interprétation : ici, le phénomène n'est jamais mis en doute et ne provoque aucune terreur puisqu'il est soumis à la grille d'interprétation chrétienne, et répond à un schéma explicitement moral de récompense ou de châtiment. Son dernier récit, "La victoria de la $\mathrm{cruz}^{7}$ ", semble marquer la fin de cette évolution dans la mesure où il s'agit d'un conte de fées, c'est-à-dire une œuvre caractérisée par l'abandon de toute ambiguïté au profit d'un univers merveilleux, coupé de la réalité, non-thétique $^{8}$. Si ce récit, en tant qu'unique conte de fées, peut paraitre isolé dans la production de Madrazo, nous verrons qu'il se rapproche des légendes religieuses antérieures, comme l'indique son titre.

Au moment de l'émergence d'une littérature enfantine spécifique, Madrazo nous livre un conte qui entretient des relations avec «La Belle au bois dormant» et qui semble adapté à la revue bourgeoise et familiale dans laquelle il paraît ${ }^{9}$. En outre, il utilise le canon du conte de fées en vue

4. P. de Madrazo, "Una impresión supersticiosa», dans No me olvides, n 9, 2 juillet 1837.

5. P. de Madrazo, "Balada en prosa. El hidalgo de Arjonilla», dans Semanario Pintoresco Español, t. XXI, $n^{\circ} 3,20$ janvier 1856 .

6. L'origine littéraire du mythe de Don Juan est l'œuvre de Tirso de Molina, El Burlador de Sevilla o el convidado de piedra (I630), qui inspira la pièce de Molière. Durant le romantisme, cette thématique est réactivée en Espagne par le poème narratif de José de Espronceda El Estudiante de Salamanca (I840), puis par la pièce de théâtre de José de Zorrilla, Don Juan Tenorio (I844). Or, ces deux auteurs majeurs du romantisme ont tous deux commencé leur carrière artistique dans $E l$ Artista.

7. P. de Madrazo, "La victoria de la cruz. Cuento de hadas", dans La Ilustración Española y Americana, $\mathrm{n}^{\circ} \mathrm{XIII}, \mathrm{I} 895, \mathrm{p}$. 2II-2I3. Comme ce texte n'a pas été publié en volume et qu'il est donc difficilement consultable, nous l'avons retranscrit en annexe (annexe I) et traduit en français. Cette traduction, tout comme les autres fragments espagnols traduits en français, a été revue par Paul Baudry (CRIMIC - Université Paris IV - Sorbonne), que je remercie chaleureusement.

8. Le terme "non-thétique» est employé pour définir le merveilleux, par opposition au fantastique, qui serait «thétique», c'est-à-dire en rapport avec la réalité de l'auteur et du lecteur, tout comme le récit réaliste, par I. Bessière dans Le Récit fantastique : la poétique de l'incertain, Nancy, BergerLevrault, 1973, p. 36-37.

9. La Ilustración Española y Americana (1869-192I) prend la suite du Museo Universal (1857-1869), qui lui-même avait succédé au Semanario Pintoresco Español (I836-1857). Ces trois revues ont en commun leur bas prix afin de viser un public large, à l'inverse d'El Artista, qui était une publication 
d'une apologie de la religion chrétienne. Cependant, il n'est pas sûr que ce mélange des genres symbolisé par la juxtaposition d'un titre évoquant la légende religieuse, "La victoire de la croix», et d'un sous-titre indiquant l'appartenance au genre du conte de fées, forme un récit moins ambigu, littérairement et moralement, que les premières productions de Madrazo.

\section{Le conte merveilleux en Espagne : un itinéraire paradoxal}

Afin d'analyser la posture de l'auteur vis-à-vis du genre du conte de fées, il nous faut tout d'abord replacer ce récit dans son contexte. Concernant le conte merveilleux, l'Espagne se caractérise par une réception paradoxale de la production européenne. Il s'agit en effet d'une réception très tardive puisque la première édition des contes de Perrault date de $1824^{10}$ : il s'agit d'une traduction parue à Paris, comprenant neuf contes tirés des Histoires du temps passé avec des moralités ${ }^{\mathrm{II}}$ (I697). L'auteur anonyme de cette édition a également traduit sans mentionner son auteur un conte de Marie-Jeanne Lhéritier, «L'Adroite Princesse ou Les Aventures de Finette» souvent attribué à Madame d'Aulnoy ("La Diestra Princesa, o las Aventuras de Finilla $\left.{ }^{\mathrm{I2}} »\right)$. La première traduction des contes de Perrault parue en Espagne date certainement du début des années $183 \mathrm{O}^{13}$. Une seconde traduction parisienne en I867 reprend celle de I824 mais en modifiant certains titres et en rétablissant les moralités en vers absentes de la première édition. Le traducteur ajoute également un conte de Madame d'Aulnoy ${ }^{14}$, «La Princesse Belle-Étoile et le Prince Chéri ${ }^{15}$ " ("El principe querido»), ainsi que le célèbre conte de Madame Leprince de Beaumont, «La Belle et la Bête» (1756) ("Linda y la Fiera»). Contrairement au premier traducteur, le second indique en couverture l'autorité multiple de ces contes bien qu'il ne précise pas quels contes

chère et élitiste, avec une dimension encyclopédique, mêlant tableaux de mœurs, articles de vulgarisation scientifique et œuvres littéraires. Ces trois revues contiennent un grand nombre de contes merveilleux.

IO. Anonyme, Cuentos de las hadas, Paris, Smith, I824.

II. Voir l'annexe ${ }^{\circ} 2$.

I2. Ce conte est extrait des Contes des fées de Madame d'Aulnoy, t. III.

13. On trouve en effet cette traduction, intitulée Barba Azul, o la Llave encantada: colección de cuentos para niños y abuelitas [anonyme], dans la liste des publications de la maison d'édition Cabrerizo, à la fin d'un ouvrage paru en I833 (P. Pérez y Rodríguez, El hombre invisible, o las ruinas de Munsterhall, novela histórica original del tiempo de las Cruzadas, Valence, Cabrerizo, I833).

14. Entre ces deux éditions, on trouve deux traductions de contes de Madame d'Aulnoy : Bella Bella o el caballero afortunado. Cuento, 1844; Cuentos de Madama d'Aulnoy, 1852.

I5. Mme d'Aulnoy, Contes nouveaux ou Les Fées à la mode, I698, t. III. 
ont été écrits par Perrault, Madame d'Aulnoy, Mademoiselle Lhéritier et Madame Leprince de Beaumont.

Avant ces traductions, Perrault était connu non pas pour ses contes mais pour son rôle dans la Querelle des Anciens et des Modernes ${ }^{16}$. On ne peut expliquer cette étonnante absence par la censure inquisitoriale car bien que de nombreux ouvrages français aient été mis à l'index pour leur impiété ou leur caractère licencieux, aucun volume de contes de fées ne s'y trouve ${ }^{17}$. La seule hypothèse restante est celle de l'influence du néo-classicisme en Espagne. S'inspirant de Muratori et de Boileau, le poéticien Ignacio Luzán (I702-I754) exprime en 1737 le même mépris de l'invraisemblance et la même défiance vis-à-vis de l'imagination ${ }^{18}$. La prose narrative brève n'apparaît même pas dans les traités littéraires néo-classiques car elle ne constitue pas un genre au même titre que la poésie lyrique, épique et dramatique. En outre, on trouve une référence dépréciative à un conte de Madame d'Aulnoy ("Gracieuse et Percinet», I697) au XvirI siècle dans la traduction d'un ouvrage de Mme de Genlis, dans lequel la narratrice, double de l'auteur, applique la doctrine néo-classique de la vraisemblance au genre du conte de fées ${ }^{19}$. Néanmoins, il est curieux que l'œuvre de Perrault, pourtant

16. Voir Reflexiones sobre el origen de los descubrimientos atribuidos a los modernos, en las que se demuestra, que nuestros más célebres filósofos han tomado la mayor parte de sus conocimientos de las obras de los antiguos, y que muchas verdades importantes sobre la religión fueron conocidas por los sabios del paganismo, par M. Dutens, recteur de Elsdon, traduit en castillan par Juan Antonio Romero, Madrid, Don Benito Cano, I792, p. 6.

17. On y trouve cependant des contes libertins et/ou orientaux : Le Sopha, conte moral (édition de 1778), de Crébillon est interdit par l'édit du I6 mars 1796; l'édit du II février I804 demande l'expurgation de l'ouvrage de Thomas-Simon Gueullette imité des Mille et Une Nuits, Les Mille et Un Quart d'heure[sic], contes tartares (I715).

18. I. de Luzán, La poética o reglas de la poesía en general y de sus principales especies, Madrid, Cátedra, 1974, 1737: "La fantasía, pues, bien como caballo ardiente, requiere mucho tiento para que no se desboque, y que el juicio cuerdo y remirado le ande siempre a la mano y la modere en sus fogosidades, para que no se desmande ni desordene, y para que sus imágenes tengan la debida proporción" (livre II, chap. I5, p. 192) : "Limagination, tout comme un cheval ardent, exige une grande prudence pour qu'elle ne s'emballe pas, et que le jugement sage et scrupuleux la tienne toujours à portée de la main et la modère dans sa fougue, pour qu'elle ne désobéisse pas et ne dévie pas de son chemin, et pour que ses images aient la bonne proportion. " Toutes les traductions françaises sont de notre fait et ont été revues par Paul Baudry (CRIMIC - Université Paris IV - Sorbonne), que je remercie chaleureusement.

19. " ;Un cuento de encantadoras! ¿Cómo es posible que semejante lectura os agrade? - Mamá, bien conozco que hago mal; pero con todo confieso que estos cuentos me gustan mucho. - ¿Y por qué causa? - Porque me divierte mucho lo que es maravilloso y extraordinario; las metamorfosis, los palacios de cristal, de oro y plata me encantan y me divierten. - ¿Pero no conoces que todo es una ficción? - Si, señora, bien sé que son cuentos. - ¿Cómo, pues, esa certeza no te los hace parecer insípidos?" (Las veladas de la quinta, comtesse de Genlis, trad. Fernando de Filleman, México, Cornelio C. Sébring, I83I, première traduction espagnole en 1788, p. 86-87) : «Un conte de fées! Comment est-ce possible 
lui-même moderne, ait été ainsi méconnue, n’ayant pas même donné lieu à un débat chez les hommes de lettres espagnols. L'absence d'un équivalent en Espagne de la fameuse Querelle - la ligne de fracture n'étant pas entre Anciens et Modernes mais entre partisans du baroque et défenseurs de la nouvelle esthétique néo-classique venue de France - contribue peutêtre aussi à expliquer cette étonnante lacune. Cependant, l'influence de la doctrine néo-classique de la vraisemblance n'a pas empêché la diffusion du conte oriental en Espagne, même si cette diffusion est bien moindre qu'en France $^{20}$.

L'intérêt du romantisme pour le populaire et pour le genre bref favorise la découverte des contes de fées des $\mathrm{XVII}^{\mathrm{e}}$ et XVIII ${ }^{\mathrm{e}}$ siècles. Or, celle-ci est paradoxalement proche en Espagne de la réception des «folkloristes» du $\mathrm{XIX}^{\mathrm{e}}$ siècle. Ainsi, les contes des frères Grimm sont traduits à partir de I850 dans divers journaux ${ }^{21}$. Il faut signaler que le premier conte des Grimm traduit est «La Belle au bois dormant», traduit "Rosa con espinas». Plus tard, certainement en I879, paraîtra un recueil d'une cinquantaine de leurs contes $^{22}$. Néanmoins, leur nom est mentionné dans la presse avant $1837^{23}$. En outre, le travail des frères Grimm était connu par la pionnière du folklorisme en Espagne, Fernán Caballero, pseudonyme de Cecilia Böhl de Faber (I796-I877). Cet écrivain connaissait parfaitement l'allemand grâce à son père Juan Nicolás Böhl de Faber ${ }^{24}$ (I770-I836). Sous ce pseudonyme

que ce genre de lecture vous plaise? - Maman, je sais que ce n'est pas bien; mais je dois tout de même avouer que ces contes me plaisent beaucoup. - Et pour quelle raison? - Parce que ce qui est merveilleux et extraordinaire m'amuse beaucoup; les métamorphoses, les palais de cristal, d'or et d'argent m'enchantent et me divertissent. — Mais ne sais-tu pas que tout cela n'est que fiction? - Oui, mère, je sais bien que ce sont des contes. - Comment donc cette certitude ne te les rendelle pas insipides?»

20. En I742, l'œuvre de Gueullette déjà évoquée (voir note I5) est traduite en espagnol par le frère Miguel de Sequeiros (Los mil y un cuartos de hora. Cuentos tártaros traducidos del idioma francés al español). En 1796, quelques récits de Galland, le traducteur français des Mille et Une Nuits, sont publiés dans la presse (Cantos Casenave, 2005, p. 24) mais il faudra attendre les années I840 pour voir apparaître une traduction complète des Mille et Une Nuits. En 1796, Francisco de Tójar publie un recueil de contes traduits de Jean-François de Saint-Lambert : Colección de cuentos morales, que contiene El Zimeo, novela americana, las fábulas orientales y El Abenaki, Salamanca, Imp. Del Editor, 1796, réédition en 1803 .

2I. Voir annexe 2.

22. Voir annexe 2.

23. Dans El Artista, on trouve une référence à Grimm non pas en tant que collecteur de contes mais en tant que philologue ("Progresos de la música en Francia», dans El Artista, t. II, I835, nº, p. II4).

24. Juan Nicolás Böhl Faber inaugure la "polémique caldéronienne», embryon de bataille romantique en Espagne, qui a lieu entre I8I4 et I8I8. Plus tard, il y aura un second affrontement entre romantiques libéraux (partisans du romantisme français) d'une part et néo-classiques et romantiques 
masculin et hispanique, Cecilia Böhl de Faber recueillit très tôt les contes populaires andalous, bien que ceux-ci n'aient été publiés que bien plus $\operatorname{tard}^{25}$. Elle ouvrit ainsi la voie à d'autres écrivains, tels qu'Antonio de Trueba (I8I9-I889), qui collecta des contes basques ${ }^{26}$, ou plus tard Juan Valera (I824-1905), qui s'intéressa à l'espace andalou tout comme Fernán Caballero $^{27}$.

La seconde moitié du XIX ${ }^{\mathrm{e}}$ siècle marque donc l'âge d'or du conte en Espagne, concernant tant la réception que la création nationale. À cette époque, les noms de Perrault et de Grimm sont devenus extrêmement célèbres : le conte de fées fait à présent partie de la culture ${ }^{28}$ et fait même son entrée dans les débats littéraires. La défiance néo-classique vis-à-vis de l'invraisemblance a laissé place à une valorisation de la fantaisie. Ainsi, en I888, un journaliste anonyme oppose les contes de Grimm, de Perrault, d'Andersen, y ajoutant même Hoffmann, qui «fortifient l'imagination en enrichissant le matériau de ses représentations» aux romans de Zola qui ne feraient qu'attrister le cœur et rendre plus insupportables encore les misères de la vie ${ }^{29}$. Si les Espagnols associent souvent tous les auteurs de

conservateurs d'autre part (partisans du théâtre «romantique» espagnol, selon la définition donnée par les frères Schlegel) à la fin des années I830.

25. F. Caballero publie son premier conte folklorique en 1849 , "La suegra del diablo» (Semanario Pintoresco Español, t. XIV, n 47, 25 nov. I849, p. 37I-373). En I859, elle publie un premier recueil de contes folkloriques déjà publiés dans des journaux : Cuentos y poesías populares andaluzas; puis en 1877 , un second: Cuentos, oraciones, adivinanzas y refranes populares e infantiles.

26. A. de Trueba, Cuentos populares, I853; Cuentos de varios colores, I866.

27. J. Valera, Cuentos y chascarrillos andaluces, 1896.

28. Dans "Estudios morales. La almohada de una joven" (Museo de las familias, t. IX, $\mathrm{n}^{\circ} 7,25$ mars I85I), le personnage principal, une jeune fille pauvre, se demande pourquoi les bonnes fées ne viennent plus au berceau des petites filles, et pourquoi elle n'a pas été aussi magnifiquement dotée que les princesses des contes de Perrault et de Madame d'Aulnoy ("se preguntaba a si misma, por qué las buenas hadas no acudian ya a la cuna de las niñas, como si no hubiese sido tan magnificamente dotada como las princesas de los cuentos de Perrault y de Mad. de Aulnoy", p. 66). En I88I, on trouve une référence à Perrault dans une publicité pour un produit contre les rides : "Es de creer ser encantamiento semejante trasformación, y que todos los genios benéficos, todas las buenas hadas de los cuentos de Perrault han cooperado a este efecto." (La Época, XXXIII, I6 juil. I88I, n I0428.) : "Il semble qu'une telle transformation est due à un enchantement, et que tous les génies bienfaisants, toutes les bonnes fées des contes de Perrault ont collaboré à cet effet.»

29. "Los cuentos de Hoffmann, de Grimm, de Perrault, de Andersen, vigorizan la imaginación enriqueciendo el material de sus representaciones [...] Pero las novelas de Zola ¿qué vacio llenan y a qué fin obedecen? [...] ¿A regocijar el ánimo? No, sino a entristecerlo. ¿A hacer más llevaderas las miserias de la vida? No, sino a hacerlas insoportables." (La Ilustración artística, Barcelone, 7 mai I888, VII, $\mathrm{n}^{\circ}$ 332, p. I55.) : «Les contes d'Hoffmann, de Grimm, de Perrault, d'Andersen, fortifient l'imagination en enrichissant le matériau de leurs représentations [...]. Mais les romans de Zola, quel vide comblent-ils et à quelle fin obéissent-ils? [...] À réjouir le cœur? Non, seulement à l'attrister. À rendre plus tolérables les misères de la vie? Non, seulement à les rendre insupportables.» 
contes sans faire de distinction, comme dans l'exemple précédent, certains comme l'écrivain Juan Valera mènent une véritable réflexion sur l'écriture du conte. Valera distingue ainsi d'un côté ceux qui «ont brodé sur le fond traditionnel des contes", à savoir Perrault, Musäus, Andersen, Madame d'Aulnoy et Madame Leprince de Beaumont, et ceux qui «se sont montrés scrupuleux et fidèles, n'ajoutant ni n'enlevant pas même un accent et se limitant à transcrire le conte de la bouche même de la vieille ou de l'homme du peuple de qui ils l'ont entendu ", tels que les frères Grimm ${ }^{30}$.

Ce retard dans la réception et dans la création du conte populaire en Espagne permet d'expliquer l'absence d'une tendance forte de la fin-de-siècle européenne, à savoir la parodie du conte de fées ${ }^{31}$, car bien que célèbres, les contes canoniques sont connus depuis trop peu de temps pour donner lieu à des parodies. Pourtant écrit durant la fin-de-siècle, le conte de Pedro de Madrazo, "La victoria de la cruz. Cuento de hadas», ne constitue donc pas une parodie du genre du conte de fées.

\section{«La victoria de la cruz» réécriture de «La Belle au bois dormant»}

Au contraire, il contient a priori tous les éléments propres au genre. Malgré l'absence de la formule consacrée de début de conte, «il était une fois» («érase una vez» ou "érase que se era» en espagnol), et de la formule de conclusion, "colorín colorado, este cuento se ha acabado ${ }^{32}$ ", le narrateur introduit le lecteur dans l'espace indéterminé du conte en commençant le récit par l'adverbe

30. "Si bien algunos autores han bordado sobre el fondo tradicional de los cuentos, como Perrault, Musaus (sic), Andersen, y las célebres señoras d'Aulnoys (sic) y Prince de Beaumont (sic), otros han hecho gala de escrupulosos y fieles, no añadiendo ni quitando un solo tilde y limitándose a trascribir el cuento de la boca misma de la vieja o del hombre del pueblo a quien se le oyeron referir. Asi, por ejemplo, han procedido los hermanos Grimm en Alemania." ("Prólogo del libro de D. Narciso Campillo, Una docena de cuentos", Juan Valera, Revista de Andalucía, t. XV, I870, p. 132.)

3I. Voir N. Châtelain, Le Conte de fées en Europe à la fin du XIXe siècle. Naissance, essence et déliquescence du conte de fées fin-de-siècle, 2005.

32. Il ne s'agit pas d'un équivalent de la formule "et ils vécurent heureux et eurent beaucoup d'enfants", qui se traduit "y fueron felices, y comieron perdices" (la traduction littérale serait : «Et ils vécurent heureux, et mangèrent des perdrix"). La formule "colorin, colorado, este cuento se ha acabado" est une expression proche des comptines pour enfants, qui n'ont d'autre fonction que de faire la rime, sans avoir de sens, du type "am, stram, gram, pic et pic et colégram» : le mot "colorín» veut dire "couleur vive», et "colorado", "coloré», ce qui donnerait "couleur colorée, ce conte est terminé». Elle constitue un rappel extra-diégétique de l'origine orale du conte, l'orateur indiquant qu'il a terminé son récit, alors que la formule française relève de l'intra-diégétique. La proximité phonétique de deux termes des formules (felices / perdices; colorado / acabado) révèle également l'oralité des contes, car les rimes étaient traditionnellement employées afin de favoriser l'apprentissage d'un récit oral. 
pouvant être à la fois spatial et temporel allá33 («là»), qui exprime l'indétermination, par opposition à allí, qui désigne un lieu précis. Le lieu de l'action n'est précisé que par l'expression «régions hyperborées » renvoyant à un point cardinal et non à un pays déterminé. De même, le temps du conte, vague lui aussi, est celui de la transition entre les «ténèbres du paganisme ${ }^{34}$ » et "l'empire de la grâce ${ }^{35}$ ", à savoir le christianisme.

À l'indication spatio-temporelle indéterminée, s'ajoute le personnel caractéristique du conte de fées : au centre du récit, on trouve un couple royal qui se meut dans un univers peuplé d'êtres surnaturels, fées, sorcières, lamies, dragons. De plus, la fonction de chaque personnage est clairement établie selon le schéma manichéen propre au conte, au moyen d'une adjectivation axiologique très claire : le roi protagoniste est "sage et vertueux ${ }^{36}$ ", alors que le roi voisin est désigné comme «le tyran Rodomonte ${ }^{37}$ »; les sorcières sont «malfaisantes» alors que les fées sont «bienfaisantes ${ }^{38}$ ». Le surnaturel est totalement intégré dans l'univers du conte puisque, dès la première phrase, le narrateur juxtapose sur le même plan les personnages surnaturels (les sorcières) et les humains (le roi et la reine), ce qui place le lecteur dans le domaine du merveilleux. Enfin, le narrateur de "La victoria de la cruz» se caractérise par son omniscience et son absence d'intervention au moyen de l'ironie, conformément au ton neutre du conte de fées.

Plusieurs éléments font de ce conte une réécriture du célèbre conte de Perrault repris par les frères Grimm, "La Belle au bois dormant». En effet, on retrouve plusieurs épisodes de ce conte : le motif de la stérilité du couple royal; la présence lors de la naissance de fées bienfaitrices et d'un être maléfique (ici une lamie) responsable du sommeil de la princesse; l'enfermement de celle-ci dans un château entouré de végétation puis sa délivrance; l'amour du prince pour elle. Il faut observer l'absence dans ce conte de la seconde partie de «La Belle au bois dormant» chez Perrault et Giambattista Basile ("Le Soleil, la Lune et Thalie», Pentaméron, I634-I636), à savoir l'affrontement de la princesse avec sa belle-mère, l'ogresse, ce qui rapproche "La victoria de la cruz» de la version de Grimm. Contrairement à d'autres contes ${ }^{39}$, "La Belle au bois dormant» qui correspond au type $4 \mathrm{IO}$

33. "La victoria de la cruz», ouvr. cité, p. 2II.

34. "Las tinieblas del paganismo" (p. 2II).

35. "La ley de gracia" (p. 2II).

36. "Sabio y virtuoso" (p. 2II).

37. "El tirano Rodomonte» (p. 2II).

38. "Brujas maléficas»; "hadas benéficas" (p. 2II).

39. "El espejo de la verdad", de Vicente Barrantes, publié dans le Semanario Pintoresco Español $\left(\mathrm{n}^{\circ} 3, \mathrm{I} 6\right.$ janvier $1853 ; \mathrm{n}^{\circ} 5,30$ janvier $1853 ; \mathrm{n}^{\circ} 7, \mathrm{I} 3$ février $\mathrm{I} 853 ; \mathrm{n}^{\circ} 9,27$ février I853) est une réécriture 
d'Aarne-Thompson ("Sleeping-Beauty») n’a pas donné lieu à des réécritures littéraires dans l'Espagne du XIX ${ }^{e}$ siècle. En revanche, on trouve dans l'espace hispanique des récits folkloriques proches des versions de Perrault et de Basile, qui mettent en scène les deux parties du conte, voire même seulement la seconde partie avec l'ogresse ${ }^{40}$. Cependant, il n'existe aucune version orale ne contenant que la première partie du conte, ce qui indique que Madrazo s'est vraisemblablement appuyé sur la version de Grimm et non pas sur une version orale hispanique.

\section{"Les fées auxiliaires du Christianisme» ou le conte de fées au service de la croyance religieuse}

Le titre du conte espagnol signale le déplacement du centre d'intérêt du conte du personnage féminin vers un élément totalement absent de l'intertexte, à savoir la guerre religieuse. Ainsi, l'axiologie manichéenne du conte se double d'une axiologie religieuse qui identifie le bien au christianisme et le mal au paganisme. Pedro de Madrazo procède à une réinterprétation personnelle de l'univers surnaturel du conte en justifiant la fonction des personnages à la lumière de la relation avec la religion : les fées sont bienveillantes à l'égard de la famille royale parce qu'elles défendent le même idéal chrétien alors que les lamies lui sont opposées en raison de leur hostilité au christianisme. Dans ce conte, l'action individuelle est donc soumise à l'action collective, comme le suggère la longue digression, qui suspend la trame principale, à propos de la réaction des différents êtres surnaturels à l'arrivée du christianisme. Trois types de réaction sont à observer : la majorité des figures païennes (ondines, elfes, sylphides, les walkyries "fausses divinités du paradis scandinave ${ }^{4 \mathrm{I}}$ ", nymphes et autres divinités des mythologies grecque, égyptienne, orientale et romaine) fuient devant "les premiers sons des cloches des sanctuaires ${ }^{42} "$; les sorcières, mais surtout les lamies, qui ont investi les palais des craintives ondines, résistent activement à la diffusion de la nouvelle religion, en faisant naufrager les bateaux des

de «Blanche-Neige» (type 709) actualisée (on trouve des allusions à la société espagnole de l'époque) et parfois parodique à l'égard du genre du conte de fées. Voir M. Amores García, " "El espejo de la verdad" de Vicente Barrantes. Una versión libre del cuento de "Blancanieves" ", Garoza, n 8, 2008, p. 9-26.

40. Voir J. Camarena Laucirica, "La bella durmiente en la tradición oral Ibérica e Iberoamericana", Revista de Dialectología y tradiciones populares, LX, 1985, p. 259-278.

4I. "Falsas divinidades del paraiso escandinavo" (p. 2II).

42. "Los primeros tañidos de las campanas de los santuarios" (p. 2II). 
missionnaires, en détruisant les églises ou encore en répandant la peste; à l'inverse, les fées sont à la fois "annonciatrices" et "auxiliaires ${ }^{43}$ " du christianisme. Si ce paragraphe peut se justifier du point de vue diégétique par les informations données à propos des motivations et des pouvoirs des personnages en présence (on apprend ainsi que le pouvoir des lamies est grand mais transitoire alors que celui des fées est plus constant), il est susceptible de recevoir une lecture allégorique qui l'éloigne un peu plus du merveilleux : on peut en effet voir dans les diverses réactions des figures païennes une représentation symbolique de l'attitude hétérogène des "païens" face au christianisme. Dans le même temps, l'évocation des maux provoqués par les lamies donne une dimension missionnaire à la délivrance de la princesse, au-delà du simple drame familial. De plus, étant endormie non pas dans le château familial mais dans un autre château où l'a enfermée la lamie qui l'a capturée, la princesse prend des allures de captive chrétienne, personnage fécond dans la tradition littéraire espagnole ${ }^{44}$.

Ce n'est pas la seule contamination du genre du conte de fées que l'on peut observer. Concernant la naissance de la princesse, on retrouve comme moyen de conjurer la stérilité royale le motif du pèlerinage, présent chez Perrault mais pas chez Grimm. Cependant, l'auteur lui donne ici une importance beaucoup plus grande, en ajoutant des détails (pèlerinage à Rome devant le sépulcre de saint Pierre), et surtout en lui conférant une efficacité là où le texte de Perrault disait "tout fut en œuvre, et rien n'y faisait », la grossesse de la Reine apparaissant plutôt due au hasard : «enfin pourtant la Reine devint grosse». Par la suite, la fonction que Propp nomme "méfait ${ }^{45}$ ", n'intervient pas lors de la dotation de la princesse par les fées, car cet épisode est supprimé du conte. Il est remplacé par un motif étranger à l'univers du conte de fées, celui du pacte diabolique. L'accouchement étant difficile, les médecins disent ne pouvoir sauver que la mère ou l'enfant : c'est à ce moment que la lamie propose au roi de sauver la reine en échange du bébé et lui fait jurer de ne jamais chercher à le récupérer. En effet, la lamie est non seulement caractérisée négativement mais se voit

43. "Estas hadas precursoras del Cristianismo le acompañaban como auxiliares en los países nuevamente rescatados de las tinieblas de la idolatría." (p. 2II) : "Ces fées annonciatrices du Christianisme l'accompagnaient en tant qu'auxiliaires dans les pays tout juste sauvés des ténèbres de l'idolâtrie.»

44. On trouve la figure de la captive chrétienne en terre musulmane dans le romancero «fronterizo", c'est-à-dire traitant de l'invasion musulmane et de la Reconquête, ainsi que dans le roman mauresque ("novela morisca»), tel que El Abencerraje (1565), d'Antonio de Villegas. Le romantisme, à la suite de Chateaubriand (Les Aventures du dernier Abencérage, 1826) et de Washington Irving (Contes de l'Alhambra, I832), a réactivé le goût pour les thématiques mauresques.

45. V. Propp, Morphologie du conte [1928], 1970. 
également qualifiée de démoniaque ${ }^{46}$. En outre, le choix de cette figure folklorique, qui est plus courante dans la légende que dans le conte de fées, n'est pas anodin puisqu'elle réunit dans son apparence les différentes composantes du diable : la beauté tentatrice et la dimension effrayante et monstrueuse (ailes et pattes de dragon ${ }^{47}$ ). De plus, par la suite, le roi luimême comprend que lorsqu'il a décidé de sauver sa femme et de donner sa fille à la lamie, il a scellé un pacte avec le diable ${ }^{48}$. Le pacte diabolique autour du nouveau-né apparaît dans la typologie d'Aarne-Thompson (motif $S_{2}$ II) non pas à propos du conte merveilleux mais du conte religieux. En effet, ce motif, en lien avec celui de la stérilité d'un couple noble, rappelle fortement la légende de Robert le Diable malgré les différences ${ }^{49}$. Cette légende médiévale française, rapidement traduite en Espagne, a connu une diffusion massive grâce à l'équivalent espagnol de la "Bibliothèque bleue", la "literatura de cordel», jusqu'au XIX ${ }^{\mathrm{e}}$ siècle ${ }^{50}$, durant lequel la légende a connu un souffle nouveau grâce à l'opéra de Meyerbeer, qui a rencontré un immense succès en Espagne comme en France : or, le premier journal espagnol à faire l'éloge de cet opéra est précisément celui auquel collabora

\footnotetext{
46. "[Las lamias] se mantenian en la ofensiva empleando sus diabólicos artificios" (p. 2II) : "Les lamies continuaient la lutte en utilisant leurs diaboliques artifices.»

47. "[La] maligna lamia [...] apareciéndose entonces de pronto en su verdadera forma de mujer con torso y rostro de deslumbradora belleza, y alas y garras de dragón [...]» (p. 2II) : "La maligne lamie, apparaissant alors tout à coup sous sa véritable forme, celle d'une femme au buste et au visage d'une éclatante beauté, avec des ailes et des griffes de dragon.»

48. "Cuando Arminda refirió a su marido la revelación que su benéfica hada le habia hecho, acabó de comprender claramente Eufranor que su juramento, al entregar su hija recién nacida, habia sido el sello de un pacto diabólico." (p. 212) : "Quand Arminda rapporta à son mari la révélation que sa bonne fée lui avait faite, Eufranor comprit alors clairement que le serment qu'il avait fait en livrant sa petite fille avait scellé un pacte diabolique.»

49. Pour une étude de cette légende, voir l'ouvrage d'É. Gaucher, Robert le Diable. Histoire d'une légende, 2003. Dans la légende de "Robert le Diable», la duchesse, après avoir fait des pèlerinages en vain, passe un pacte symbolique avec le diable, en promettant de lui donner son enfant si elle réussit à en avoir un. À l'inverse, ici, la stérilité est vaincue grâce à la piété des époux et le pacte n'est passé qu'après la naissance, et non plus par la mère mais par le père, désireux de sauver son épouse. En outre, dans la légende médiévale, le diable n'apparait jamais explicitement : la naissance de l'enfant est entourée de signes apocalyptiques mais le jeune Robert est surnommé «le Diable» à cause de sa cruauté sans apparaître comme le fils du diable (ce qui sera néanmoins le cas dans l'opéra de Meyerbeer du XIx ${ }^{\mathrm{e}}$ siècle). Chez Madrazo, le personnage diabolique a une forme propre, celle de la lamie.

50. Pour une étude de la diffusion de «Robert le Diable» en Espagne, voir J. M. Cacho Blecua, "Estructura y difusión de Roberto el diablo", dans Formas breves del relato (colloque, fév. 1985), Saragosse, Casa de Velázquez, 1986, p. 35-56; A. Robert Lauer, "La espantosa y maravillosa vida de Roberto el Diablo y sus transmutaciones literarias hispánicas», dans M. Insúa et L. Peres (éd.), Monstruos y prodigios en la literatura hispánica, Madrid, Iberoamericana, Francfort, Vervuert, 2009, p. 167-I80.
} 
Pedro de Madrazo dans sa jeunesse ${ }^{51}$. De même, la conversion au christianisme de Florimundo, prince païen et cruel, fils du tyran Rodomonte, n'est pas sans rappeler celle de Robert le Diable.

On observe donc une superposition de la légende chrétienne et du conte de fées. Ainsi, la victoire sur le dragon, qui est certes un épisode typique du conte de fées, peut être lue selon une autre grille de lecture. Malgré la référence à Persée ${ }^{52}$, Eufranor, arborant une croix rouge sur sa cuirasse, rappelle plutôt saint Georges de Cappadoce. Le dragon, tout comme la lamie et les reptiles garnissant la fosse du château ${ }^{{ }_{3}}$, cessent d'être de simples figures folkloriques connotées négativement pour devenir des avatars du diable, non nommé. On comprend ainsi la puissance de la croix qui trouble le dragon et du signe de croix qui suffit à désenchanter la princesse, remplaçant le baiser profane du prince (chez Grimm) ou sa seule présence (chez Perrault). Dans ce conte, les traditionnels objets magiques sont presque tous $^{54}$ remplacés par l'arme caractéristique du merveilleux chrétien, le signe de croix, omniprésent dans la littérature hagiographiquess. De même, l'eau baptismale acquiert une valeur magique à la fin du récit puisqu'elle entraîne l'exil des "esprits maléfiques ${ }^{56}$ ", lors du baptême de Florimundo et de ses

5I. Dès I831, date de la première en France, on trouve une référence à l'opéra de Meyerbeer (Cartas españolas, décembre i83I, p. 3II). Dans El Artista, en I835, l'opéra est qualifié de «composition d'un ordre supérieur", "gigantesque et sublime» ("composición de un orden superior: gigantesca y sublime composición", dans "Progresos de la música en Francia", art. cité, p. II5), "comprenant des concerts d'anges et des orgies de démons" ("compuesta de conciertos de ángeles y de orgías de demonios", dans "Variedades», El Artista, t. II, I835, n 26, p. 312).

52. La fée Esterela dévoile en rêve à la reine comment désenchanter la princesse : "[El dragón] se prestaría, manso como un cordero, a servirle de guía dentro del castillo, y de cabalgadura aérea, más ligera que el Pegaso de Perseo." (p. 2I2) : "Le dragon, doux comme un agneau, lui servirait de guide à l'intérieur du château, et de monture aérienne, plus légère que le Pégase de Persée. "

53. "Para llegar hasta [la princesa] habia que atravesar un peligroso puente, angosto como un listón de madera, tendido sobre un profundo foso, en cuyo obscuro y cenagoso fondo bullia una asquerosa caterva de endriagos y reptiles de horrendo aspecto y descomunal tamaño." (p. 2II) : "Pour arriver jusqu’à la princesse, il fallait traverser un pont périlleux, étroit comme une planche de bois, qui surplombait de profondes douves, obscures et fangeuses, au fond desquelles grouillait une foule d'endriagues et de reptiles immenses et affreux.»

54. On trouve néanmoins dans le conte un objet dénué de toute connotation religieuse : la pierre rouge extraite de la crête du dragon, laquelle devient un talisman permettant d'accéder au château.

55. Pour ne citer qu'un exemple, dans la somme hagiographique d'Alonso de Villegas, inspirée de la Légende dorée, de saint Grégoire et de Métaphraste, le signe de croix permet à saint Antoine de faire réapparaître le pied qu'un pénitent s'était lui-même coupé (A. de Villegas, Fructus sanctorum, Cuenca, Juan Masselin, 1594, discurso quinto, p. 21).

56. "Al recibir Florimundo y sus partidarios las aguas del bautismo, al eco de los cánticos con que en un improvisado templo celebraba la Iglesia la sagrada ceremonia, todos los espiritus maléficos que hasta entonces habian arraigado su pertinaz imperio en aquellos dominios, los abandonaron, formando clamorosa legión que se dispersó dirigiendo su rumbo hacia otros paises.» (p. 213) : «Lorsque Florimundo 
partisans. L'interpénétration des genres de la légende chrétienne et du conte folklorique n'est pas une nouveauté. La légende de "Robert le Diable» possède ainsi de nombreux motifs communs avec le conte, tels que le don d'objets par un auxiliaire magique christianisé (non plus une fée mais un ange), la victoire sur le responsable du méfait ${ }^{57}$, la découverte du faux héros, le sénéchal, et le mariage final avec la fille de l'Empereur ${ }^{58}$. Cependant, Madrazo effectue le chemin inverse en prenant pour cadre le conte de fées et en y introduisant des éléments de la littérature religieuse : au lieu d'une folklorisation de la légende religieuse, on assiste à une christianisation du conte de fées, qui n'est peut-être pas sans risque pour le genre lui-même.

\section{Le conte de fées et la légende religieuse : une difficile cohabitation?}

Dans le conte de fées européen de la même époque, on trouve également des éléments religieux. Néanmoins dans ces contes, les éléments du merveilleux païen et du merveilleux chrétien apparaissent de façon clairement distincte : dans «Oriane vaincue» de Jean Lorrain, la fée est vaincue par le chevalier chrétien Amadis; dans "La Princesse Neigefleur», du même Lorrain, la magicienne Imogine perd ses pouvoirs le jour sacré de l'Épiphanie. Au contraire, chez Madrazo, la frontière est poreuse puisqu'on trouve dans le camp chrétien et dans le camp païen des figures du merveilleux païen (fées d'un côté, lamies de l'autre). Il s'agit donc non pas d'un affrontement mais d'une contamination des genres. Comme l'indique Nathalie Châtelain, les écrivains de contes de fées de la fin-de-siècle utilisent la parodie comme moyen de renouveler un genre poussiéreux et un personnel usé (les fées) en ayant recours au merveilleux chrétien ${ }^{9}$.

Si on ne trouve chez l'écrivain espagnol aucun signe d'ironie vis-à-vis du conte de fées, les nombreuses interpolations de motifs provenant de la

et ses partisans reçurent l'eau baptismale, et que retentit l'écho des cantiques au son desquels l'Église célébrait la cérémonie sacrée dans un temple improvisé, tous les esprits maléfiques qui jusqu’alors avaient établi leur empire tenace dans ces contrées, les abandonnèrent, formant une légion retentissante qui se dispersa pour se tourner vers d'autres pays.»

57. Dans cette légende l'auteur du méfait est double : il s'agit à la fois de Robert lui-même avant sa conversion, et des musulmans, vus comme des envahisseurs impies.

58. Ce dénouement est celui de la version profane qui est celle qui a été diffusée : le miracle du XIv ${ }^{\mathrm{e}}$ a donné lieu à un dit au Xve siècle, sur lequel s’appuie la version de I496 qui a inspiré la "Bibliothèque bleue» en France et la "literatura de cordel» en Espagne. À l'inverse, la première version, dans le roman du XII ${ }^{\mathrm{e}}$, puis l'exemplum du XIII ${ }^{\mathrm{e}}$ siècle, comprenait une fin plus conforme à la visée édifiante, Robert devenant ermite (Cacho Blecua, 1986, p. 36-37).

59. N. Châtelain, Le Conte de fées en Europe à la fin du XIXe siècle, ouvr. cité, p. 205-208. 
littérature religieuse entraînent toutefois une certaine dénaturation du genre. En effet, la traditionnelle fin heureuse est toute relative puisque la "victoire de la croix» est certes un fait mais le mariage entre Estrella et Florimundo est empêché par l'assassinat de celui-ci par son propre père après qu'il a appris sa conversion. Néanmoins, la négativité de cette mort est atténuée grâce à son interprétation chrétienne comme martyre ${ }^{60}$. De plus, la disparition du prince dans ce conte n'est pas aussi intolérable qu'elle pourrait l'être dans un conte de fées traditionnel dans la mesure où Florimundo n'est pas un héros canonique. Ainsi, celui-ci brille certes par sa beauté et son courage, caractéristiques du prince de conte de fées, mais également par sa haine sans borne à l'égard des chrétiens ${ }^{61}$. Il est donc au début du côté des opposants puisque les lamies ont projeté une union entre Estrella et lui afin de récupérer le royaume d'Eufranor et ainsi d'assurer la victoire du paganisme. Ce n'est qu'à la fin du récit qu'il devient un héros potentiel dans la mesure où il se convertit après avoir vu la beauté de la princesse et la sainteté du royaume d'Eufranor. Dans la littérature religieuse, il n'est pas rare de trouver un anti-héros se transformant en héros : c'est même la structure de la plupart des vies de saints, qui se repentent de leurs péchés, ainsi que de "Robert le Diable». Cependant, dans le genre du conte, il manque à la trajectoire héroïque de Florimundo l'épisode fondamental de la quête. S'il rêve de sauver Estrella, dont il est tombé amoureux en entendant la rumeur de son extraordinaire beauté, ce n'est pourtant pas lui mais Eufranor qui désenchante la princesse. Il s'agit là d'une grave infraction aux règles du conte de fées dans la mesure où un personnage assume deux fonctions normalement distinctes (roi-père / héros-quêteur), ce qui conduit à déposséder un autre personnage de son unique fonction. Si les personnages assumant les diverses fonctions établies par Propp peuvent varier selon les contes, il n'existe à notre connaissance aucun conte où le père est aussi le héros qui sauve la princesse et où le prince meurt avant d'épouser celle-ci. Cela peut se justifier par la situation initiale qui met en scène un anti-héros païen appelé seulement plus tard à se convertir : entre temps, seul le père pouvait assumer la délivrance de la princesse.

60. "Al ejecutarse la bárbara sentencia, se dejó oír en el cielo un coro invisible que cantaba el himno de los mártires." (p. 213) : "Au moment même où cette sentence barbare fut exécutée, un chœur invisible qui chantait l'hymne des martyrs se fit entendre dans le ciel.»

6I. "El Principe a quien Estrella estaba destinada era el hermoso Florimundo, cuyas proezas pregonaba la fama, hijo del tirano Rodomonte, terror de las naciones circunvecinas [...]. Florimundo odiaba a los cristianos.» (p. 2II) : «Le Prince auquel Estrella était destinée était le beau Florimundo, dont on vantait les prouesses, fils du tyran Rodomonte, terreur des nations voisines [...]. Florimundo haïssait les chrétiens.» 
Mais cette logique rend presque impossible la traditionnelle fin de conte de fées puisque, s'il n'a pas participé au sauvetage de la princesse, le prince ne s'est pas rendu digne de l'épouser, malgré sa conversion. Là où un conte traditionnel aurait nécessité une nouvelle épreuve, cette fois destinée au prince, l'auteur choisit d'éliminer le prince, nouvelle infraction majeure au genre. Si l'immense majorité des contes folkloriques ont une fin heureuse, il faut rappeler l'existence des Schreckmärchen (contes d'effroi) ou Warnmärchen (contes d'avertissement ${ }^{62}$ ), dont s'inspire par exemple "Le Petit Chaperon rouge» : ce sont des récits composés pour mettre les enfants en garde, et qui se terminent par le châtiment du personnage fautif. La fin tragique du prince pourrait être expliquée par cette tradition s'il ne s'était pas converti, comme châtiment de son impiété : à l'inverse, il apparaît comme une victime innocente de la cruauté de son père, dont la seule fonction dans le conte est précisément l'assassinat de son fils, crime qui reste quant à lui impuni. Or, cette fin contredit aussi bien le genre du conte que celui de la légende religieuse : malgré la victoire sur les diaboliques lamies, et la conversion du prince païen, celui-ci disparait et avec lui, la possibilité d'avenir du royaume chrétien. En effet, Eufranor voyait en un Florimundo converti le gage de prospérité de son royaume ${ }^{63}$. Bien qu'il nuance la dimension tragique de sa mort, et permette de mettre en lumière par contraste la barbarie du personnage resté païen, le martyre du prince ne correspond pas à ce que le conte avait programmé. Le dénouement remet donc en doute ce qui semblait être le projet d'écriture de Madrazo, à savoir un conte de fées christianisé.

\section{Une réécriture personnelle en dehors des genres littéraires?}

Sans prétendre se substituer aux autres lectures, une hypothèse psychanalytique peut permettre d'expliquer ces brèches dans la logique du texte. En effet, le déplacement de la fonction du héros, du prince vers le père de la princesse, indique un désir oedipien du père pour la fille, de même que l'élimination à la fin du récit du rival potentiel, Florimundo, par une

\footnotetext{
62. Ces termes ont été employés pour la première fois par M. Rumpf dans une monographie sur «Le Petit Chaperon rouge» (dans P. Delarue et M.-L. Tenèze (éd.), Le Conte populaire français, Paris, Maisonneuve et Larose, 1976, I, p. 383).

63. "Si Florimundo no fuese un idólatra y a mí me fuera dado recobrar a mi hija (pensaba él), quizás una alianza matrimonial podría asegurar la paz y la integridad de mi reino para lo futuro.» (p. 2II): «Si Florimundo n'était pas un idolâtre et qu'il m’était donné de retrouver ma fille (pensait-il), une alliance matrimoniale pourrait peut-être assurer la paix et l'intégrité de mon royaume à l'avenir.»
} 
autre figure paternelle. Par conséquent le dénouement du conte n'est pas le mariage du prince et de la princesse mais la reconstitution du noyau familial centré sur lui-même et donc propice à l'inceste. En effet la transformation du héros-quêteur avait entraîné une autre modification du conte initial : dans celui-ci, la princesse étant endormie dans le château de ses parents eux-mêmes enchantés (motif supprimé par Madrazo), c'est naturellement un élément extérieur (le prince) qui résout la situation; à l'inverse, dans "La victoria de la cruz», la princesse ayant été ravie à ses parents et placée dans un autre château, le but du conte sera de la ramener dans le château de ses parents, qui représente la cellule familiale. Il n'y a donc pas de véritable évolution puisque le dénouement n'établit pas un équilibre supérieur à l'équilibre initial, comme c'est normalement le cas dans le conte, mais ne fait que rétablir un équilibre initial perdu, celui de la famille réunie. Par ailleurs, les modifications effectuées autour du personnage féminin par rapport à l'intertexte peuvent aller dans le sens de notre hypothèse. Chez Madrazo, Estrella ne s'endort pas à l'adolescence après avoir touché un fuseau, selon la malédiction prononcée lors de la cérémonie des dons, mais à la naissance même, lorsqu'elle est enlevée par la lamie après le pacte passé par son père. Ici, le sommeil n'est donc pas justifié par un adoucissement de la malédiction mortelle comme chez Perrault, et doit avoir une autre fonction : bien que son corps grandisse durant son sommeil, psychiquement la princesse reste à l'état d'enfant. De plus, dans le récit, n'ayant aucune action propre, elle n'a d'autre fonction que celle de fille et donc de possible objet du désir paternel.

Cette hypothèse peut être corroborée par le premier récit écrit par Pedro de Madrazo, qui traite explicitement du désir incestueux entre frère et sœur, et implicitement entre père et fille ${ }^{64}$. De plus, on retrouve dans « $L a$ victoria de la cruz» le motif de la décapitation ${ }^{65}$, qui est une représentation de la castration, châtiment fantasmé de l'inceste, aussi présent dans «Yago

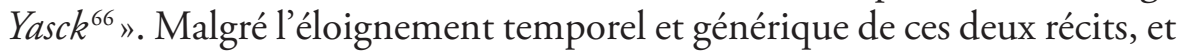
au-delà de l'écriture consciente qui mêle conte de fées et légende religieuse,

64. Dans «Yago Yasck», le personnage éponyme empêche la consommation de l'inceste entre son fils et sa fille qui ignorent leur lien de parenté, tout en entretenant une relation trouble avec sa propre fille.

65. «En una oscura mazmorra [Rodomonte] le hizo cortar la cabeza [a Florimundo]» (p. 213) : «Dans un sombre cachot, [Rodomonte] lui fit couper la tête."

66. À la fin de "Yago Yasck», Ángela meurt décapitée par deux portes, son frère finit aveugle et son père borgne : dès son étude sur "L'homme au sable» d'Hoffmann, Freud avait mis en avant le lien entre la peur liée à la perte de la vue et l'angoisse de castration (S. Freud, "L'inquiétante étrangeté», dans L'Inquiétante étrangeté et autres essais, 2007, p. 23I). 
il est possible de voir dans «La victoria de la cruz» une préoccupation plus personnelle de l'auteur, pouvant expliquer certaines incohérences apparentes du récit.

Si l'on peut envisager cette superposition de genres littéraires comme un échec, suivant une logique de court-circuit mutuel, on peut aussi la considérer comme la force du récit : n'étant pleinement ni un conte de fées ni une légende religieuse, "La victoria de la cruz. Cuento de hadas" est à la fois l'un et l'autre. Il s'agit ainsi d'un conte d'une rare complexité, qui délaisse la linéarité et la transparence de l'exemplum et du conte pour enfants au profit d'une généricité ambiguë et d'une écriture poétique mises au service d'une visée apostolique, sans neutraliser les obsessions personnelles de l'écrivain. 


\section{"LA VICTORIA DE LA CRUZ. CUENTO DE HADAS", PEDRO DE MADRAZO}

$1 \begin{aligned} & \text { LLÁ EN los TIEMpos en que la ley de gracia empezaba a clarear en } \\ & \text { las regiones hiperbóreas entre las tinieblas del paganismo, y en que } \\ & \text { las brujas maléficas lo revolvian y trastornaban todo con sus perversas }\end{aligned}$ hechicerias, habia un rey muy sabio y virtuoso, llamado Eufranor, como el antiguo y famoso pintor de Corinto, el cual amaba con pasión a su bella esposa la reina Arminda. Sólo le faltaba a este rey para ser enteramente feliz tener descendencia a quien dejar a su muerte la corona: porque en aquel pais, cuyo nombre callan las historias, ya en tan remota época la monarquia era hereditaria sin distinción de sexos, y lo mismo subian al trono las hembras que los varones. Hizo la Reina una larga y penosa peregrinación a Roma, donde oró con gran fervor ante el sepulcro de San Pedro, para que el poderoso Príncipe de los Apóstoles fuese propicio a sus votos: $y$ al cabo de un año comprendió que iba a ser madre, lo cual colmó al Rey de alegría. En acción de gracias, edificó en la capital de sus Estados un hermoso templo al Santo Apóstol, su protector: las hadas benéficas, que, con su reina Esterela al frente, se habian en aquella época declarado protectoras de todas las gentes de buena fe, y que, sin saberlo los dos esposos, aunque presumiéndolo por el buen éxito constante de sus empresas, estaban prontas a ayudarles en todos sus piadosos propósitos, inspiraron tal actividad a los constructores, que en menos de quince dias vieron los vasallos maravillados erigido el templo y en disposición de ser decorado, pintado y alhajado con cuanta magnificencia daba de si el arte en aquel pais.

Pero el alumbramiento de la Reina, al llegar su tiempo, se presentó dificultoso, en términos que los médicos del Rey llegaron a pronosticar que la criatura no podria lograrse sin sacrificar a la madre, y que para salvar a ésta habria que sacrificar a la criatura. En tan terrible trance, Eufranor que idolatraba a Arminda y preferia su vida a todos los bienes del universo, dijo a sus médicos: “Sálvese la Reina a toda costa!" Mas los ministros y áulicos, mirando al bien del Estado antes que al afecto del Monarca hacia su esposa, puestos de acuerdo con los médicos, tramaron secretamente el modo de que la criatura se salvase a costa de la madre: y habian logrado ya con engaño que se administrase a la 
Reina a media noche cierto funesto brebaje, cuando la camarera encargada de ejecutarlo se sintió acometida de un profundo letargo a la hora concertada, sin poder llevar la traidora copa a los labios de Arminda. Presentóse en su lugar tomando su figura una maligna lamia, la cual, penetrando sola en el dormitorio donde la Reina yacia presa de mortales congojas y casi a punto de expirar, hizo que Eufranor cerrase las puertas, y apareciéndose entonces de pronto de su verdadera forma de mujer con torso y rostro de deslumbradora belleza, y alas y garras de dragón, le dijo con voz de irresistible encanto:

- Yo salvo a la dulce compañera de tu vida sin que perezca el fruto que lleva en sus entrañas, si me cedes la criatura, a quien te prometo hacer dichosa, y si, renunciando por completo todos tus derechos sobre ella, me juras que no has de procurar jamás disputarme su posesión.

- iLo juro! - respondió el Rey en medio del estupor que le embargaba el sentido.

E inmediatamente la lamia se acercó al lecho, tomó en sus brazos a Arminda, se la entregó al Rey llena de júbilo y de vida, y recogiendo una hermosa niña que la madre, sin sentirlo, habia dejado entre las sábanas, como un capullito desprendido de un ramo de flores, desapareció por la ventana del dormitorio, que se abrió de par en par por si sola, llevándose por los aires la preciosa carga, galardón de su perfidia, en cuya frente estampó un beso, sonoro como un estallido, que trocó en terror el asombro del Rey.

Esto pasaba de noche a la incierta claridad de una luna medio velada por errantes nubecillas: $y$ los cortesanos que salieron al parque del palacio al saber el estupendo suceso, vieron como una blanca ráfaga lejana que rápidamente se dirigía al ocaso, en la cual se vislumbraba a intervalos un rutilante lucero. Era la marca de esclavitud puesta por la lamia hechicera a la niña en medio de la frente al emprender con ella el vuelo: marca que sólo lucía en la sombra, y con la claridad se amortiguaba.

La lamia que con tal astucia arrebató su hija a la reina Arminda habitaba con otras compañeras suyas un soberbio palacio submarino, con columnas de cristal, bóvedas de ópalo y zafiro y guirnaldas colgantes de perlas y corales: palacio que habian dejado desierto las ondinas de los antiguos coros de genios de las aguas, en cuanto oyeron resonar en las riberas donde ejercian su imperio los primeros tañidos de las campanas de los santuarios. Menos timidas que sus predecesoras, cuyos ardides tenían por objeto seducir a los incautos que se entregaban demasiado confiados al dulce atractivo de las aguas corrientes, para ahogarlos en su fondo, las lamias arrostraban el odiado clamor de los sagrados bronces y los cantos de la liturgia cristiana: se mantenian en la ofensiva empleando sus diabólicos artificios, y en guerra abierta contra las 
nuevas ideas que iban regenerando el mundo. Suscitando tempestades, hacian naufragar las naves portadoras de misioneros evangélicos: impeliendo los huracanes, derribaban las torres de las iglesias en que aun no estaban enhiestas las cruces: cabalgando como briosos demonios en invisibles legiones sobre las brisas nocturnas, sembraban los infecciosos gérmenes que recogian en las pútridas emanaciones de los pantanos, difundiendo los estragos de la peste, y con ellos el espanto y la desolación: males que sólo habian de cesar con el triunfo definitivo de la Cruz.

Cuando las lamias salian de su palacio para hacer sus maleficios, tomaban formas adecuadas al acto que habian de poner por obra. En las grandes calamidades públicas, se identificaban, por decirlo así, con los agentes naturales más destructores; para consumar sus agresiones contra las personas aisladas o las familias, se valian de formas ya seductoras, ya repugnantes o formidables; unas veces eran hermosas sirenas, otras arpias o brujas harapientas, y obraban separadamente, como lo hizo la lamia que se apoderó de la recién nacida Princesa de nuestro cuento.

Mas el poder de estos genios maléficos no era tan absoluto que estuviera la humanidad supeditada a su funesto capricho; era, por el contrario, excepcional y transitorio, como son siempre los males en el mundo. Opuestas a las lamias, habia hadas benéficas, genios asimismo invisibles, dotados de un poder más constante y eficaz que el de aquéllas. Por su mediación en las cosas de los mortales de sana intención y bien inclinados, habia siempre subsistido en la tierra la noción de lo bueno y de lo justo, y estas hadas precursoras del Cristianismo le acompañaban como auxiliares en los paises nuevamente rescatados de las tinieblas de la idolatría. A medida que estos genios bienhechores iban allanando el camino a los monjes benedictinos, propagadores de la luz evangélica, las falsas divinidades del paraíso escandinavo, las walkirias, que daban la inmortalidad con el hidromel a los héroes inmolados en los campos de batallas: las silfides, genios del aire: las elfas, genios de la luz y de las sombras, y los demás espiritus de los bosques, de las montañas, de los lagos y de los rios, fueron huyendo en confuso tropel a sepultarse en los abismos de las antiguas supersticiones, con sus compañeras las diosas y ninfas y demás personificaciones de los genios celestes, terrestres, marinos e infernales del Olimpo griego y de las mitologías egipcia, oriental y romana. Sólo subsistieron como más pertinaces, y por divina tolerancia, para probar y acrisolar la fe de los nuevos cristianos, las lamias y brujas, las cuales fijaron sus dominios principalmente en los paises del Norte, entre los sencillos y crédulos habitantes de las montañas.

La hermosa criatura que una lamia traidora robó al amor de la reina Arminda, y a quien las perversas hechiceras llamaban Estrella por la que de 
noche brillaba en su frente, permanecía encerrada en un solitario castillo oculto en la espesura de una enmarañada selva, a la cual nadie osaba acercarse por los imponentes rugidos de fieras sobrenaturales que se decía resonaban en sus contornos. Alli estaba entregada a un no interrumpido y profundo sueño, sin darse cuenta de su estado, ocupando el centro de una deliciosa glorieta de flores y plantas olorosas, en lecho de jazmines y madreselva. Para llegar hasta ella habia que atravesar un peligroso puente, angosto como un listón de madera, tendido sobre un profundo foso, en cuyo obscuro y cenagoso fondo bullia una asquerosa caterva de endriagos y reptiles de horrendo aspecto y descomunal tamaño. En medio del letargo en que se hallaba sumergida Estrella, crecía y aumentaba de dia en día su hermosura, sin que nadie visiblemente cuidase de sostener aquella preciosa vida. Las lamias la tenían destinada para esposa del Principe pagano más grande, más valeroso y más enemigo de Cristo que habia a la sazón en toda la tierra septentrional de Europa. La guarda de Estrella estaba confiada a un monstruoso dragón de cuerpo escamoso y zarpas de tigre, que instalado en la única puerta exterior del castillo, no dormía nunca, y lanzaba de sus encendidos ojos miradas como rayos, $y$ de sus horrendas fauces atronadores aullidos.

El Principe a quien Estrella estaba destinada era el hermoso Florimundo, cuyas proezas pregonaba la fama, hijo del tirano Rodomonte, terror de las naciones circunvecinas, al cual sólo tenía a raya en sus veleidosas invasiones el prudente y poderoso Eufranor. Colindaban los Estados de ambos reyes, y Eufranor miraba con recelo dilatarse los dominios de su vecino, a causa principalmente de las victorias de su hijo. "Si Florimundo no fuese un idólatra y a mi me fuera dado recobrar a mi hija (pensaba él), quizás una alianza matrimonial podría asegurar la paz y la integridad de mi reino para lo futuro." Pero habia que desechar esas ilusiones: Florimundo odiaba a los cristianos, y en cuanto a él, el juramento que habia prestado al venir al mundo Estrella, le quitaba toda esperanza de volverla a ver.

Entretanto el tiempo pasaba, y Arminda no volvió a ser madre. Estrella cumplió diez y ocho años: las lamias hicieron cundir por todas partes la fama de su extraordinaria belleza, aumentada por el prodigio del lucero que de noche resplandecía en su frente, y el principe Florimundo, sin haberla visto jamás, se enamoró ciegamente de ella por misteriosas sugestiones de su exaltada fantasia, y con una pasión tanto más vehemente cuanto más dificultosa se le representaba la empresa de libertarla de la encantada mansión que la retenía invisible a los vivientes.

Una noche que Arminda, lamentándose de su esterilidad, se habia encomendado con mayor fervor que de costumbre a su patrono el apóstol San Pedro, 
apareciósele en sueños el hada Esterela, quien la reveló el lugar donde estaba hechizada su hija, y que para librarla del poder de las lamias que la destinaban al tálamo del terrible Florimundo, era menester que Eufranor la desencantase: lo que sólo lograría penetrando en el formidable castillo donde hacía diez y ocho años que estaba dormida, y haciendo sobre su frente la señal de la cruz. Para llevar a feliz término tan arriesgada empresa, habia que luchar con el terrible dragón que guardaba la puerta exterior del castillo: vencerle, cortándole la cresta; sacar de ella una piedrecilla roja como un rubi, donde estaba reconcentrada toda la fiereza y malignidad del monstruo; valerse de esa piedra, a cuyo simple contacto se fundian los más fuertes hierros, para irse abriendo paso por las siete puertas interiores del edificio, hasta el peligroso puente del foso que aislaba la glorieta donde Estrella dormía su interminable sueño. El paso del quebradizo y angosto puente no habia de intentarse en manera alguna: el foso habia de salvarse de otra manera; el mismo dragón vencido por Eufranor, dado que éste tuviese la suerte de separarle de un tajo la misteriosa cresta, perdida toda su ferocidad, se prestaría, manso como un cordero, a servirle de guia dentro del castillo, y de cabalgadura aérea, más ligera que el Pegaso de Perseo, para franquear el horrendo foso. Hecho esto, nada podía ya oponerse a que Eufranor, haciendo la señal de la cruz en la frente de Estrella, deshiciese el encanto que la tenía secuestrada, volviese la Princesa de su sueño y recobrase su libertad.

Cuando Arminda refirió a su marido la revelación que su benéfica hada le habia hecho, acabó de comprender claramente Eufranor que su juramento, al entregar su hija recién nacida, habia sido el sello de un pacto diabólico, y entonces, ardiendo en deseos de reparar su culpa y de proporcionar días de júbilo a todo su reino con el rescate de la heredera de su corona, se aprestó sin demora a llevar a efecto la arriesgada expedición del castillo encantado. Armóse de pies a cabeza: puso sobre su coraza una cruz roja, otra en su casco de oro y otra en su escudo: se hizo calzar las espuelas: tomó su mandoble mejor templado, su maza de desarmar y espada damasquina, y guiado por una fuerza invisible, llegó a la selva en medio de la cual estaba el castillo maldito. No escuchó en sus contornos silbidos de serpientes, ni rugidos de leones, pero si el feroz aullido del dragón que le guardaba, al cual se llegó resuelto. Acobardado el monstruo, que nunca habia visto cruces, ante las que resplandecian en el arnés del Rey, cejó al aproximársele éste; inclinó la horrible cabeza, con un sordo gruñido: aprovechó este momento Eufranor para dirigirle a la cresta un tajo de mandoble: se la cortó a cercén, cayendo al suelo con un río de sangre negra y humeante: la bestia lanzó un tremendo alarido que resonó en toda la selva, dando formidables coletazos que tronchaban árboles y batiendo las alas con metálicos estallidos que sonaban como truenos, pero sin atreverse a acometer a Eufranor: y cuando éste sacó de la 
cresta, derribada en tierra, la piedra roja que habia de servirle de talismán para penetrar en el castillo, el dragón, depuesta toda su fiereza, se prestó a seguirle sumiso, atravesando con él las siete puertas interiores, y a dejarse montar, y aun espolear, para ponerle de un bote, entre salto y vuelo, al otro lado del foso y a la entrada misma de la embalsamada glorieta donde dormía Estrella entre rosas y jazmines. Todo salió conforme Esterela lo habia anunciado. Pocos días después, la hermosa Princesa, hija de Eufranor y de Arminda, era aclamada heredera de la corona con indecible júbilo de todo aquel reino, que adoraba a su excelente y glorioso Monarca.

Furiosas las lamias viendo que se les habia escapado la presa y que se les frustraba su propósito de entregar la princesa a Florimundo para que éste, a la muerte de Eufranor, reclamase el trono y los Estados del difunto rey como legitima herencia de su esposa, y una vez dueño de ellos, derribase todas sus iglesias, persiguiese a los cristianos y restituyese en aquellos dominios el culto de los idolos, idearon conseguir por medio de una sangrienta guerra lo que no podian lograr pacificamente. Para esto sugirieron al impetuoso Principe los deseos de apoderarse de una de las provincias del reino de Eufranor lindante con los Estados de su padre el tirano Rodomonte: pero se les frustró también este segundo designio, tan pérfido como el primero, porque no contando con la nobleza propia de las almas jóvenes y con el prestigio o imperio que la belleza por si sola ejerce en los corazones de los verdaderos héroes, no ajenos por cierto los más estrenuos y belicosos a los sentimientos de generosidad y abnegación, sucedió que Florimundo, antes de buscar pretexto alguno para mover guerra a Eufranor, quiso ver por si mismo a la hija de éste, de cuya hermosura por simple relación se habia prendado; y habiéndose a este efecto disfrazado de romero, para penetrar con más facilidad en su palacio, quedó tan cautivo de su incomparable gentileza, de su sobrehumana beldad y modestia, y del ambiente de felicidad y santidad que en aquella mansión se respiraba, y que él nunca habia disfrutado hasta entonces, que volvió a la corte de su padre con el ánimo enteramente cambiado. Ya no pensó más en obtener por la violencia la codiciada posesión de aquella joya, que podía quizá honrada y pacificamente hacer suya purificando su alma de toda pasión bastarda y pagana, y haciéndose digno de unir su nervuda mano, tan a menudo teñida de sangre en los combates, con la delicada y purísima mano de Estrella. Pensó seriamente que la felicidad que de aquella unión se prometía, sólo habia de ser completa para él en el tranquilo gremio de la Iglesia fundada por el que vino a establecer el reino de la paz y del amor entre los hombres... Florimundo, en suma, se hizo cristiano, y siguiendo el ejemplo de su amado príncipe, abrazó la nueva Ley la parte más granada de la corte, ignorante de todo el Rey, que se hallaba en la 
frontera opuesta de sus Estados ejecutando actos de crueldad en los indefensos habitantes de una tribu vecina. Al recibir Florimundo y sus partidarios las aguas del bautismo, al eco de los cánticos con que en un improvisado templo celebraba la Iglesia la sagrada ceremonia, todos los espiritus maléficos que hasta entonces habian arraigado su pertinaz imperio en aquellos dominios, los abandonaron, formando clamorosa legión que se dispersó dirigiendo su rumbo hacia otros paises. Tuvo el animoso Principe la marcial franqueza de declarar su conversión a su padre, y el feroz tirano, exasperado y rabioso, le mandó prender sigilosamente, y en una obscura mazmorra le hizo cortar la cabeza. Al ejecutarse la bárbara sentencia, se dejó oír en el cielo un coro invisible que cantaba el himno de los mártires.

Sobre el sepulcro de Florimundo luce todavía, después de tantos siglos, una rutilante estrella, más hermosa y esplendente que la que puso la lamia hechicera en la frente de la hija de Eufranor.

\section{Traduction française \\ «La victoire de la croix. Conte de fées»}

En des temps immémoriaux où l'empire de la grâce commençait à illuminer les régions hyperborées plongées dans les ténèbres du paganisme, et où les envoûtements pervers des maléfiques sorcières mettaient tout sens dessus dessous, il était une fois un roi fort sage et vertueux, appelé Eufranor, comme le vieux et célèbre peintre de Corinthe, et qui aimait passionnément sa belle épouse, la reine Arminda. Pour que ce roi fût parfaitement heureux, il ne lui manquait qu'une descendance à qui léguer son royaume à sa mort : car dans ce pays, dont les histoires taisent le nom, à cette époque pourtant si lointaine, la monarchie était déjà héréditaire sans distinction de sexe, et les femmes montaient sur le trône aussi bien que les hommes. La Reine fit un pèlerinage long et pénible à Rome, où elle pria avec une grande ferveur devant le sépulcre de Saint Pierre, afin que le puissant Prince des Apôtres soit favorable à ses vœux : et au bout d'un an, elle comprit qu'elle allait être mère, ce qui combla le Roi de joie. Comme action de grâce, il fit construire dans la capitale de ses États un magnifique temple au Saint Apôtre, son protecteur : les fées bénéfiques, qui, avec à leur tête leur reine Esterela, s'étaient à cette époque déclarées protectrices de toutes les personnes de bonne foi, et qui, à l'insu des deux époux, même si le succès constant de leurs desseins le leur laissait présager, étaient disposées à leur venir en aide dans toutes leurs pieuses entreprises, inspirèrent une telle activité aux constructeurs, qu'en moins de quinze jours les vassaux émerveillés virent le temple érigé 
et prêt à être décoré, peint et orné avec toute la magnificence dont l'art de ce pays était capable.

Mais l'accouchement de la Reine, le moment venu, présenta des difficultés, tant et si bien que les médecins du Roi en vinrent à annoncer que l'enfant ne pourrait naître sans qu'on sacrifie la mère, et que pour sauver celle-ci il faudrait sacrifier l'enfant. Face à une si terrible situation, Eufranor, qui idolâtrait Arminda et préférait sa vie à tous les biens du monde, dit à ses médecins : «Sauvez la Reine à tout prix!» Mais les ministres et les courtisans, considérant le bien de l'État plutôt que les sentiments du Monarque envers son épouse, et s'étant mis d'accord avec les médecins, combinèrent en secret un moyen pour que l'enfant fût sauvé au détriment de la mère : ils avaient déjà fait en sorte que l'on administrât perfidement à la Reine quelque funeste breuvage à minuit, lorsque la servante chargée de l'apporter se sentit assaillie par une profonde léthargie à l'heure prévue, et ne put porter la traîtresse coupe aux lèvres d'Arminda. Une maligne lamie se présenta à sa place, ayant pris son apparence, et pénétrant seule dans la chambre où gisait la Reine en proie à de mortelles souffrances et presque sur le point d'expirer, elle fit fermer les portes à Eufranor, puis apparaissant soudain sous sa véritable forme, celle d'une femme au buste et au visage d'une éclatante beauté, avec des ailes et des griffes de dragon, elle lui dit d'une voix au charme irrésistible :

"Je sauverai la douce compagne de ta vie sans que périsse le fruit qu'elle porte dans ses entrailles, si tu me cèdes l'enfant, que je te promets de rendre heureux, et si, renonçant absolument à tous tes droits sur lui, tu me jures que tu ne tenteras jamais de me disputer sa possession.

— Je le jure!» répondit le Roi frappé d'une stupeur qui paralysait son jugement.

Et aussitôt la lamie s'approcha du lit, prit Arminda dans ses bras, la livra au Roi pleine de joie et de vie, et recueillant une jolie petite fille que la mère, sans s'en rendre compte, avait laissée dans les draps, comme un bourgeon tombé d'un bouquet de fleurs, elle disparut par la fenêtre de la chambre, qui s'ouvrit toute seule de part en part, emportant dans les airs le précieux paquet, récompense de sa perfidie, sur le front duquel elle apposa un baiser, sonore comme une explosion, qui transforma en terreur la stupéfaction du Roi.

Cela se passait de nuit, à la lueur incertaine d'une lune à demi voilée par des petits nuages errants : et les courtisans qui, ayant appris l'extraordinaire événement, sortirent dans le parc du palais, virent comme un lointain éclair blanc qui se dirigeait rapidement vers le couchant, sur lequel on apercevait par intermittence une étoile rutilante. C'était la marque de 
l'esclavage qu'avait imprimée l'ensorceleuse lamie au milieu du front de la petite fille en prenant son envol avec elle : marque qui ne brillait que dans l'ombre, et qui s'atténuait avec la clarté.

La lamie qui avait arraché sa fille à la reine Arminda avec tant d'astuce habitait avec des compagnes un superbe palais sous-marin, avec des colonnes de cristal, des voûtes d'opale et de saphir et des guirlandes de perles et de coraux : ce palais avait été déserté par les ondines des anciens chœurs des génies des eaux, dès qu'elles eurent entendu résonner sur les rives où elles exerçaient leur empire les premiers sons des cloches de sanctuaires. Moins timides que celles qui les avaient précédées, dont les ruses avaient pour objet de séduire les imprudents qui s'abandonnaient trop confiants au doux charme des eaux courantes, pour les noyer au fond de celles-ci, les lamies affrontaient la clameur haïe des bronzes sacrés et les chants de la liturgie chrétienne : elles continuaient la lutte en utilisant leurs diaboliques artifices, et restaient en guerre ouverte contre les nouvelles idées qui régénéraient le monde peu à peu. En provoquant des tempêtes, elles faisaient naufrager les navires qui transportaient des missionnaires évangéliques; en excitant les ouragans, elles renversaient les tours des églises sur lesquelles les croix ne se dressaient pas encore; en chevauchant les brises nocturnes comme de fougueux démons, formées en légions invisibles, elles semaient les germes infectieux qu'elles recueillaient des putrides émanations des marécages, diffusant les ravages de la peste, et avec eux l'épouvante et la désolation : maux qui ne pourraient cesser qu'avec le triomphe définitif de la Croix.

Quand les lamies sortaient de leur palais pour jeter leurs maléfices, elles prenaient des formes adéquates à l'action qu'elles allaient mettre en œuvre. Dans les grandes catastrophes collectives, elles s'identifiaient, pour ainsi dire, aux agents naturels les plus destructeurs; pour consommer leurs agressions contre les personnes isolées ou les familles, elles se servaient de formes soit séductrices, soit répugnantes ou formidables; parfois c'étaient de belles sirènes, d'autres fois des harpies ou des sorcières en haillons, et elles œuvraient de façon indépendante, comme le fit la lamie qui s'empara de la petite Princesse de notre conte.

Mais le pouvoir de ces créatures maléfiques n'était pas absolu au point que l'humanité fût soumise à leur funeste caprice; il était au contraire exceptionnel et transitoire, comme le sont toujours les maux dans le monde. $\grave{A}$ l'opposé des lamies, il y avait des fées bénéfiques, créatures également invisibles, dotées d'un pouvoir plus constant et efficace que celui de leurs ennemies. Grâce à leur médiation dans les affaires des mortels bien intentionnés et enclins au bien, la notion du bien et du juste avait toujours subsisté sur 
la terre, et ces fées annonciatrices du Christianisme l'accompagnaient en tant qu'auxiliaires dans les pays tout juste sauvés des ténèbres de l'idolâtrie. À mesure que ces créatures bienfaitrices préparaient la voie aux moines bénédictins, propagateurs de la lumière évangélique, les fausses divinités du paradis scandinaves, les walkyries, qui donnaient par l'hydromel l'immortalité aux héros immolés sur les champs de bataille, les sylphides, génies de l'air, les elfes, génies de la lumière et des ombres, et les autres esprits des bois, des montagnes, des lacs et des rivières, s'enfuirent en une foule confuse pour aller s'enterrer dans les abîmes des anciennes superstitions, avec leurs compagnes les déesses, les nymphes et autres personnifications des génies célestes, terrestres, marins et infernaux de l'Olympe grec et des mythologies égyptienne, orientale et romaine. Il ne resta à cause de leur ténacité, et de la tolérance de Dieu, qui cherchait à mettre à l'épreuve et à examiner la foi des nouveaux chrétiens, que les lamies et les sorcières, qui se fixèrent principalement dans les pays du Nord, au milieu des simples et crédules habitants des montagnes.

La belle enfant qu'une lamie traîtresse vola à l'amour de la reine Arminda et que les perverses sorcières appelaient Estrella, à cause de l'étoile qui brillait la nuit sur son front, restait enfermée dans un château solitaire et dérobé aux regards par un bois épais et luxuriant, dont personne n'osait s'approcher à cause des impressionnants rugissements des bêtes surnaturelles qui résonnaient, disait-on, à ses abords. Là elle était plongée dans un sommeil profond et continu, sans se rendre compte de son état, occupant le centre d'une délicieuse charmille de fleurs et de plantes parfumées, sur une couche de jasmins et de chèvrefeuille. Pour arriver jusqu'à la princesse, il fallait traverser un pont périlleux, étroit comme une planche de bois, qui surplombait de profondes douves, obscures et fangeuses, au fond desquelles grouillait une répugnante foule d'endriagues et de reptiles immenses et affreux. Dans la léthargie dans laquelle se trouvait Estrella, sa beauté croissait et augmentait de jour en jour, sans que personne ne s'occupât visiblement de maintenir cette précieuse vie. Les lamies l'avaient destinée à être l'épouse du Prince païen le plus grand, le plus courageux et le plus hostile au Christ qu'il y avait à l'époque dans toute la terre septentrionale de l'Europe. La garde d'Estrella était confiée à un monstrueux dragon au corps squameux et aux griffes de tigre, qui, installé devant l'unique porte extérieure du château, ne dormait jamais : ses yeux ardents lançaient des regards comme des éclairs, et des hurlements assourdissants sortaient de son horrible gosier.

Le Prince auquel Estrella était destinée était le beau Florimundo, dont on vantait les prouesses, fils du tyran Rodomonte, terreur des nations voisines, 
qui n'était tenu à distance dans ses invasions velléitaires que par le prudent et puissant Eufranor. Les États des deux rois étaient contigus et Eufranor voyait avec méfiance les territoires de son voisin s'étendre, principalement à cause des victoires de son fils. «Si Florimundo n'était pas un idolâtre et qu'il m'était donné de retrouver ma fille (pensait-il), une alliance matrimoniale pourrait peut-être assurer la paix et l'intégrité de mon royaume à l'avenir ». Mais il fallait rejeter ces illusions : Florimundo haïssait les chrétiens, et quant à lui, le serment qu'il avait prêté à la naissance d'Estrella lui ôtait toute espérance de la revoir.

Le temps passait, et Arminda n'eut pas d'autre enfant. Estrella eut dixhuit ans : les lamies divulguèrent partout la nouvelle de son extraordinaire beauté, accrue par le prodige de l'étoile qui brillait la nuit sur son front, et le prince Florimundo, sans l'avoir jamais vue, tomba aveuglément amoureux d'elle par de mystérieuses suggestions de son imagination exaltée, et avec une passion d'autant plus violente que l'entreprise de la délivrer de la demeure enchantée qui la maintenait invisible aux yeux des vivants lui semblait difficultueuse.

Une nuit, alors qu'Arminda, se lamentant de sa stérilité, s'était recommandée avec plus de ferveur que de coutume à son patron l'apôtre Saint Pierre, elle vit en songe la fée Esterela, qui lui révéla le lieu où sa fille était ensorcelée, et que pour la délivrer du pouvoir des lamies qui la destinaient au lit nuptial du terrible Florimundo, il fallait qu'Eufranor la désenchantât : il n'y parviendrait qu'en pénétrant dans le formidable château où elle était endormie depuis dix-huit ans, et en faisant sur son front le signe de croix. Pour mener à bien une entreprise si risquée, il fallait lutter contre le terrible dragon qui gardait la porte extérieure du château : le vaincre, en lui coupant la crête; en sortir une petite pierre rouge comme un rubis, où était concentrée toute la férocité et la malignité du monstre; se servir de cette pierre, au simple contact duquel les fers les plus résistants fondaient, pour se frayer un passage au travers des sept portes intérieures de l'édifice, jusqu'au pont périlleux de la fosse qui isolait la charmille où Estrella dormait interminablement. Il ne fallait en aucune façon s'aventurer sur ce pont fragile et étroit; il fallait franchir la fosse d'une autre façon; le dragon vaincu par Eufranor, étant donné que celui-ci aurait la chance de séparer d'un coup d'épée la mystérieuse crête, toute sa férocité perdue, doux comme un agneau, lui servirait de guide dans le château et de monture aérienne, plus légère que le Pégase de Persée, pour passer l'affreuse fosse. Cela fait, rien ne pouvait plus s'opposer à ce qu'Eufranor, en faisant le signe de croix sur le front d'Estrella, annulât le charme qui la maintenait 
séquestrée, à ce que la Princesse sortît de son sommeil et qu'elle ne recouvrît sa liberté.

Quand Arminda rapporta à son mari la révélation que sa fée bénéfique lui avait faite, Eufranor comprit alors clairement que le serment qu'il avait fait en livrant sa petite fille avait scellé un pacte diabolique, et alors, brûlant du désir de réparer sa faute et d'offrir des jours de fête à tout son royaume en sauvant l'héritière de son trône, il s'apprêta sans délai à mener à bien la périlleuse expédition du château enchanté. Il s'arma de la tête aux pieds : il mit une croix rouge sur sa cuirasse, une autre sur son casque d'or et une autre sur son bouclier; il se fit mettre ses éperons; il prit sa rapière la mieux trempée, sa massue à désarmer et son épée damasquinée, et guidé par une force invisible, il arriva à la forêt au milieu de laquelle se trouvait le château maudit. Il n'entendit à ses abords ni les sifflements des serpents, ni les rugissements des lions, mais le féroce hurlement du dragon qui le gardait, vers lequel il se dirigea avec résolution. Le monstre, qui n'avait jamais vu de croix, face à celles qui luisaient sur le harnais du Roi, recula intimidé à l'arrivée de celui-ci, et pencha son horrible tête avec un grognement sourd; Eufranor profita de ce moment pour lui asséner au niveau de la crête un coup de rapière : il la lui coupa à ras, et elle tomba au sol au milieu d'une mare de sang noir et fumant; la bête lança un cri terrible qui résonna dans toute la forêt, en donnant de formidables coups de queue qui renversaient les arbres, et en battant des ailes avec des bruits métalliques semblables au tonnerre, mais sans oser attaquer Eufranor; et quand celui-ci sortit de la crête, tombée à terre, la pierre rouge qui devait lui servir de talisman pour pénétrer dans le château, le dragon, toute sa férocité éliminée, se prêta à le suivre soumis, traversant avec lui les sept portes intérieures, et à se laisser monter, et même éperonner, pour le mener d'un bond, mi-sautant, mivolant, de l'autre côté de la fosse et juste à l'entrée de la charmille embaumée où Estrella dormait, au milieu des roses et des jasmins. Tout se passa comme Esterela l'avait prédit. Quelques jours plus tard, la belle Princesse, fille d'Eufranor et d'Arminda, était proclamée héritière de la couronne à la joie indicible de tout le pays, qui adorait son excellent et glorieux Monarque.

Furieuses de voir que leur proie leur avait échappé et que l'on contrariait leur projet de livrer la princesse à Florimundo pour que celui-ci, à la mort d'Eufranor, réclamât le trône et les États du défunt roi comme héritage légitime de son épouse, et qu'une fois à leur tête, il détruisît toutes les églises, poursuivît les chrétiens et rétablît dans ces territoires le culte des idoles, les lamies eurent l'idée d'obtenir au moyen d'une guerre sanglante ce qu'elles ne pouvaient réussir pacifiquement. Pour cela, elles suggérèrent à 
l'impétueux Prince le désir de s'emparer de l'une des provinces du royaume d'Eufranor contigu aux États de son père le tyran Rodomonte; mais ce second dessein, aussi perfide que le premier, fut également contrarié, car c'était compter sans la noblesse propre aux âmes jeunes et le prestige ou l'empire que la beauté elle-même exerce sur les cœurs des véritables héros, les plus vaillants et belliqueux n'étant certainement pas étrangers aux sentiments de générosité et d'abnégation : il arriva que Florimundo, au lieu de chercher un prétexte pour entrer en guerre contre Eufranor, voulut voir par lui-même la fille de celui-ci, dont il s'était épris par simple ouï-dire; et s'étant pour cela déguisé en pèlerin, pour pénétrer plus facilement en son palais, il fut tellement séduit par sa grâce incomparable, par sa beauté et sa modestie surhumaines, et par l'ambiance de bonheur et de sainteté qui régnait dans cette demeure, et dont il n'avait jamais joui auparavant, qu'il revint à la cour de son père totalement transformé. Il ne pensa plus à obtenir par la violence la possession convoitée de ce bijou, qu'il pouvait peut-être faire sien honnêtement et pacifiquement en purifiant son âme de toute passion bâtarde et païenne, et en se rendant digne d'unir sa main nerveuse, si souvent tachée de sang dans les combats, à celle, délicate et pure, d'Estrella. Il pensa sérieusement que le bonheur que cette union promettait ne serait complet que dans le giron de l'Église, fondée par celui qui vint établir le royaume de la paix et de l'amour entre les hommes... Florimundo, en somme, devint chrétien, et suivant l'exemple de son prince bien-aimé, la part la plus illustre de la cour embrassa la nouvelle Loi, à l'insu du Roi, qui se trouvait à la frontière opposée de ses États en train d'accomplir des actes de cruauté contre les habitants sans défense d'une tribu voisine. Lorsque Florimundo et ses partisans reçurent l'eau baptismale, lorsque retentit l'écho des cantiques au son desquels l'Église célébrait la cérémonie sacrée dans un temple improvisé, tous les esprits maléfiques qui jusqu’alors avaient établi leur empire tenace dans ces contrées, les abandonnèrent, formant une légion retentissante qui se dispersa pour se diriger vers d'autres pays. Le courageux Prince eut la franchise martiale de déclarer sa conversion à son père, et le féroce tyran, exaspéré et enragé, le fit secrètement emprisonner, et dans un sombre cachot lui fit couper la tête. Au moment même où cette sentence barbare fut exécutée, un chœur invisible qui chantait l'hymne des martyrs se fit entendre dans le ciel.

Sur le sépulcre de Florimundo brille encore, après tant de siècles, une luisante étoile, plus belle et splendide que celle qu'avait posée la lamie ensorceleuse sur le front de la fille d'Eufranor. 


\author{
ANNEXE 2 \\ TRADUCTIONS ESPAGNOLES DES CONTES \\ DE PERRAULT ET DE GRIMM AU XIX ${ }^{e}$ SIÈCLE
}

\title{
CHARLES PERRAULT
}

Cuentos de las hadas, París, Smith, I824;

réédition chez Rosa et Bouret, I872 :

"La caperucilla encarnada» ("Le Petit Chaperon rouge», Histoires du temps passé avec des moralités, 1697)

«Las hadas» ("Les Fées», HTP)

"El barba azul» («La Barbe bleue», HTP)

"La hermosa del bosque durmiente» ("La Belle au bois dormant», HTP)

"El gato maestro, o con botas» ("Le Chat botté», HTP)

"La cenizosa, o la chinelilla de vidrio» ("Cendrillon», HTP)

«Riquet del copete» ("Riquet à la houppe», HTP)

«El pulgarcillo» («Le Petit Poucet», HTP)

"La diestra princesa, o las aventuras de Finilla» ("L'Adroite princesse ou Les

Aventures de Finette», Marie-Jeanne Lhéritier, 1996)

"Piel de asno» («Peau d'Âne», HTP)

Cuentos de las hadas, por Carlos Perrault, Ma Leprince de Beaumont, etc.

Nueva edición ilustrada con gran número de viñetas, por G. Staal,

Paris, Garnier hermanos, I867 :

"La caperucilla encarnada»

"Las hadas"

«Barba azul»

"La hermosa del bosque durmiente»

"El gato maestro o con botas"

"La cenicienta o la chinelita de vidrio"

"Riquet del copete»

"El pulgarcillo»

"La diestra princesa o las aventuras de Finilla» 
"Piel de asno"

"El príncipe querido» («La Princesse Belle-Étoile et le prince Chéri», dans

Madame d'Aulnoy, Contes nouveaux ou les Fées à la mode, I698, t. III) "Linda y la fiera» ("La Belle et la Bête», Madame Leprince de Beaumont, I756)

Cuentos de hadas, Carlos Perrault, trad. por J. Coll y Vehí, Barcelone (Librería de El Plus Ultra, Administración de la Maravilla); Madrid (Don M. Quijarro, Don Emilio Font);

Barcelone, imp. Narciso Ramírez, I862:

"Las hadas»

"Barba azul»

"Amapola» («Le Petit Chaperon rouge»)

"Pellejo de asno» («Peau d'Âne»)

"El ratoncillo blanco» (?)

"La cenicienta o la chinelita de cristal»

"La reina y la campesina» (?)

"Roquete del copete» («Riquet à la houppe»)

"La hada Berliqueta» ("Brimborion», conte attribué à tort à Perrault ou

à Mme d'Aulnoy)

"Caga-chitas» («Le Petit Poucet»)

"El gato embotado» («Le Chat botté»)

"La hermosa en el bosque encantado"

"Los deseos ridiculos» («Les Souhaits ridicules», HTP)

"Linda y la fiera"

Los Cuentos de Perrault, traducidos del francés por T. Lix, Paris, Garnier hermanos, I884 :

«Caperucita encarnada»

"Las hadas»

"Barba azul»

"La hermosa durmiente del bosque»

"Micifuz el de las botas"

"Cenicienta o la zapatilla enana"

"Riquet el del copete»

"Pulgarito»

"La sagaz princesa o las aventuras de Finette»

"Piel de asno" 


\section{JACOB ET WILHELM GRIMM}

Museo de los niños (Madrid, I847-I850) :

"Los cuentos de la familia, por los hermanos Grimm (Continuación). Rosa de Eglantier», décembre I850 ( LLa Belle au Bois Dormant ou La Princesse Fleur-d'Épine»——Dornröschen», KHM 50, I8I2).

Semanario Popular (Madrid, I862-I865) :

"La liebre y el erizo", I862, n 4, p. 3I ("Le Lièvre et le Hérisson» — «Der Hase und der Igel», KHM I87, I843).

"El huso, la lanzadera y la aguja», I862, n 8, p. 63 ("Fuseau, navette et aiguille» — "Spindel, Weberschiffchen und Nadel», KHM I88, I843). «Los tres hermanos», I862, n II, p. I05 («Les Trois Frères» — «Die drei Brüder», KHM I24, I8I5).

"Los regalos de los hermanos», I862, $\mathrm{n}^{\circ} \mathrm{I} 5$, p. II3-II4 (?).

"Los tres pelos de oro del diablo", I862, n²4, p. I67-8 («Le Diable et ses trois cheveux d'or» ou «Les Trois Cheveux d'or du Diable» — «Der Teudel mit den drei goldenen Haaren", KHM 29, I8I2).

"La infiel Eva», I862, n² 25, p. I98-199 («Les Différents Fils d'Ève»——Die ungleichen Kinder Evas", KHM I80, I843).

"Los tres ramos verdes", I862, $\mathrm{n}^{\circ}$ 27, p. $2 \mathrm{I} 4$ ("Les Trois Rameaux verts» -

"Die drei grünen Zweige», KHM 206, Légendes de l'enfance, appendice à partir de la $2^{\mathrm{e}}$ édition).

«El judio de las espinas», I862, n 29, p. 23I-232 («Le Juif dans les épines»"Der Jude im Dorn", KHM IIO, I8I5).

"La sepultura», I862, n 40, p. 319-320 ("La Tombe»— "Der Grabhügel», KHM 195, 1850).

"Juan el Fiel», I862, n 42, p. 33I ("Jean-le-fidèle» ou «Le Fidèle Jean" —

"Der treue Johannes", KHM 6, I819).

"El arpa maravillosa», I864 (?).

"Viaje por mar», I864 ("L’Envie de voyager» — «Up Reisen gohn», KHM I43, I8I9).

\section{La Educanda (Madrid, I86I-I865) :}

"Los huéspedes importunos. Cuento de Grimm (traducido del original alemán)", B., 8 février $1863, \mathrm{n}^{\circ} 9$ ("De la racaille ou Les Vagabonds» — «Das Lumpengesindel», KHM ıо, I8ı2). 
"La manirrota. Cuento de Grimm», 24 février I863, n II («Les Petits Nœuds» — "Die Schlickerlinge», KHM 156, I819). "Las tres hilanderas. Cuento de Grimm (traducido del original)", J.S.B., I6 octobre I863, n 34 ("Les Trois Fileuses» — «Die drei Spinnerinnen», KHM I4, I8I2).

"Los tres herederos afortunados. Cuento de Grimm (traducido del original)", B., I6 décembre I863, $\mathrm{n}^{\circ} 50$ ("Les Trois Enfants-gâtés de la fortune»«Die drei Glücksinder», KHM 70, I819).

Cuentos escogidoàs de los hermanos Grimm, trad. del alemán por José S. Viedma. Madrid, Gaspar y Roig (fecha deducida a partir de otras ediciones, post. a I866; David Roas indique 1879) :

"Las tres hilanderas» («Les Trois Fileuses» — «Die drei Spinnerinnen», KHM I4, I8I2).

"Los regalos de los gnomos» («Les Présents du peuple menu» — «Die

Geschenke des kleinen Volkes", KHM I82, à partir de la 6 édition, I850). "El hijo ingrato» ("Le Fils ingrat» — «Der undankbare Sohn», KHM I45, I8I5).

"Juan el fiel» ("Jean-le-fidèle ou Le Fidèle Jean» — "Der treue Johannes»,

KHM 6 (à partir de la $2^{\mathrm{e}}$ édition) I819).

"El judío en las espinas» («Le Juif dans les épines» — «Der Jude im Dorn», KHM IIO, I8I5).

"El rey de las ranas» ("Le Roi-Grenouille ou Henri-le-Ferré», "Le Roi

Grenouille ou Henri de Fer» ou «La Fille du Roi et la Grenouille»-

"Der Froschköng oder der eiserne Heinrich», KHM I, I8I2).

"La reina de las abejas» ("La Reine des abeilles» — «Die Bienenkönigin»,

KHM 62, $2^{\mathrm{e}}$ édition, I819).

"Hermanito y hermanita» («Frérot et Sœurette» ou "Petit-Frère et Petite-

Sour" — "Brüderchen und Schwesterchen", KHM II, I8I2).

"El pobre y el rico» («Le Pauvre et le Riche» — «Der Arme und der Reiche», KHM 87, vol. 2, I815).

"Blancanieve y Rojarosa» ("Neigeblanche et Roserouge» — «Sneeweisschen

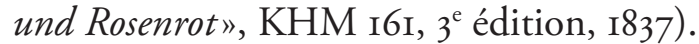

«Ruiponche» ("Raiponce»— «Rapunzel», KHM I2, I8I2). «La carga ligera» ("La Gardeuse d'oies à la fontaine» — «Die Gänsehirtin am Brunnen", KHM 179, I843).

«Rosa con espinas» («La Belle au Bois Dormant» ou «La Princesse Fleurd'Épine» — «Dornröschen», KHM 50, I8I2). 
"Los músicos de Brema» («Les Musiciens de la fanfare de Brême» ou «Les

Musiciens de Brême» — «Die Bremer Stadtmusikanten", KHM, $2^{\mathrm{e}}$ édition, I819).

"La cenicienta" ("Cendrillon» — "Aschenputtel», KHM 2I, I8I2).

"El pescador y su mujer» ("Le Pêcheur et sa femme» — "Von dem Fischer un syner Fru», KHM I9, I8I2).

"Los dos compañeros de viaje» («Les Deux Compagnons de route»——Die beiden Wanderer", KHM, 5 édition, I843).

"Dios te socorra» ("Nourriture céleste» ou «Dieu nourrit les malheureux»

— "Gottes Speise», KHM 205, Légendes de l'enfance, appendice à partir

de la $2^{\mathrm{e}}$ édition).

"El señor Sabelo-todo» («Docteur Je-Sais-Tout» — «Doktor Allwissend»,

KHM 98, I8I5).

"Juan en la prosperidad» ("Jean-la-Chance» «Hans im Glück», KHM 83,

à partir de la $2^{\mathrm{e}}$ édition, I8I5).

"El hombre de la piel de oso» ("L'Homme à la peau d'ours» — «Der Bären-

häuter», KHM IOI, I8I5).

"Juanita y Juanito» ("Yorinde et Yoringue»— «Jorinde und Joringel», KHM 69, I815).

«El joven gigante» ("Le Jeune Géant» — «Der junge Riese», KHM 90, I8I5).

«El oso y el reyezuelo» («Le Roitelet et l'Ours» — «Der Zaunkönig und der

Bär», KHM IO2, I8I5).

«Los doce cazadores» («Les Douze Chasseurs»— «Die zwölfJäger», KHM 67, I812).

"El sastrecillo valeroso» («Sept d'un coup», «Le Hardi Petit Tailleur» ou "Le

Vaillant Petit Tailleur» — "Das tapfere Schneiderlein», KHM 20, I8I2). "El festín celestial» ("Le Banquet céleste» — «Die himmlische Hochzeit»,

KHM 209, à partir de la $2^{\mathrm{e}}$ édition dans Légendes de l'enfance; avant à la place de KHM I2I).

"Los tres pelos de oro del diablo» («Le Diable et ses trois cheveux d'or ou les

Trois Cheveux d'or du Diable» — «Der Teudel mit den drei goldenen Haaren", KHM 29, I8I2).

"Tom Pouce» («Tom Pouce» — «Daumesdick», KHM 37, I819).

"El dinero llovido del cielo» («L'Argent du Ciel»—— «ie Sterntaler», KHM

I53, $\mathrm{I}^{\text {re }}$ edition, I8I2, à la place de KHM 83).

"Los tres herederos afortunados» ("Les Trois Enfants-gâtés de la fortune»

— "Die drei Glücksinder", KHM 70, 2 édition, I819).

"Historia de uno que hizo un viaje para saber lo que era miedo" ("Histoire d'un qui s'en alla pour apprendre le tremblement", "Conte de celui qui 
s'en alla pour connaître la peur, Histoire de celui qui s'en alla apprendre la peur» — "Märchen von einem, der auszog das Fürchten zu lernen», $\mathrm{KHM}_{4}$, I8I2).

«La madre vieja» («La Vieille Maman» — «Das alte Mütterchen», KHM 208, Légendes de l'enfance, appendice à partir de la $2^{\mathrm{e}}$ édition).

"La ondina del estanque» ("L'Ondine dans son étang» — «Die Nixe im Teich», KHM I8I, 5 édition, I843).

"Los tres ramos verdes» ("Les Trois Rameaux verts» — «Die drei grünen Zweige», KHM 206, Légendes de l'enfance...).

"Los seis compañeros que lo consiguen todo" ("Six à qui rien ne résiste»

— "Sechse kommen durch die ganze Welt», KHM 7I à partir de la $2^{\mathrm{e}}$ édition).

«La liebre y el erizo» ("Le Lièvre et le Hérisson» — «Der Hase und der Igel», KHM I87, $5^{\mathrm{e}}$ édition, I843).

«El huso, la lanzadera y la aguja» ("Fuseau, navette et aiguille»— «Spindel,

Weberschiffchen und Nadel», KHM I88, 5 édition, I843).

"El abuelo y el nieto» ("Le Vieux Grand-Père et Son Petit-fils» — "Der alte Frossvater und der Enkel», KHM 78, I8I2).

"La mesa, el asno y la vara maravillosa» ("Petite-table-sois-mise, l'Âne-à-l'or et Gourdin-sors-du-sac» — «Rischen deck dich, Goldesel und Knüppel aus dem Sack», KHM 36, I812).

"Los tres hermanos» ("Les Trois Frères» — «Die drei Brüder», KHM I24, I8I5).

"La sepultura» («La Tombe»— «Der Grabhügel», KHM 195, 6édition I850).

«La manirota» («Les Petits Nouds» — «Die Schlickerlinge» KHM I56, I8I9).

«Los enanos mágicos» («Les Lutins» — «Die Wichtelmänner», KHM 40 I812).

"La hija de la Virgen María» («L'Enfant de Marie ou L'Enfant de la bonne Vierge" — «Marienkind» KHM 3, I8I2).

"Los huéspedes importunos» («De la racaille» ou «Les Vagabonds» — «Das Lumpengesindel», KHM IO, I8I2).

"Por faltar un clavo" ("Le Clou»— «Der Nagel», KHM I84, 5 édition, I843). 


\section{Bibliographie}

Aarne Antti, The types of folktales. A classification and bibliography, traduit et augmenté par $\mathrm{S}$. Thompson, $2^{\text {nde }}$ révision, Helsinki, 1987.

Amores García Montserrat, "El espejo de la verdad" de Vicente Barrantes. Una versión libre del cuento de Blancanieves", Garoza, n ${ }^{\circ}$ 8, 2008, p. 9-26.

Cacho Blecua Juan Manuel, «Estructura y difusión de Roberto el diablo», dans Formas breves del relato, (colloque fév. 1985), Zaragoza, Casa de Velázquez, 1986, p. 35-56.

Camarena Laucirica, Julio, "La bella durmiente en la tradición oral Ibérica e Iberoamericana», Revista de Dialectología y tradiciones populares, LX, 1985, p. 259-278.

Cantos Casenave Marieta, "El cuento en el siglo XVIII : una propuesta para el rescate y estudio de un género olvidado", Cuadernos dieciochistas, $\mathrm{n}^{\circ} 3,2002$, p. II3-I32.

-, Antología del cuento español del siglo XVIII, Madrid, Cátedra, 2005.

Châtelain Nathalie, Le conte de fées en Europe à la fin du XIX siècle. Naissance, essence et déliquescence du conte de fées fin-de-siècle, Université Nancy 2, 2005.

Delarue Paul et Tenèze Marie-Louise, Le conte populaire français, Paris, Maisonneuve et Larose, 1976.

Freud Sigmund, "L'inquiétante étrangeté», dans L'inquiétante étrangeté et autres essais, Paris, Gallimard, 2007.

Gaucher Elisabeth, Robert le diable. Histoire d'une légende, Paris, Honoré Champion, 2003.

Propp Vladimir, Morphologie du conte [1928], Paris, Seuil, I970.

RoAs David, De la maravilla al horror. Los inicios de lo fantástico en la cultura española (I750-I860), Pontevedra, Mirabel, 2006.

Robert Lauer A., «La espantosa y maravillosa vida de Roberto el Diablo y sus transmutaciones literarias hispánicas ", dans M. Insúa et L. Peres (éd.), Monstruos y prodigios en la literatura hispánica, Madrid, Iberoamericana; Frankfurt, Vervuert, 2009, p. I67-I80.

Rodríguez Gutiérrez, Borja (éd.), Cuentos, Pedro de Madrazo, Santander, Servicio de Publicaciones, Universidad de Cantabria, 2004. 